\title{
4,7-Disubstituted 7H-Pyrrolo[2,3-d]pyrimidines and Their Analogs as Antiviral Agents against Zika Virus
}

\author{
Ruben Soto-Acosta, Eunkyung Jung, Li Qiu, Daniel J. Wilson, Robert J. Geraghty *(D) and Liqiang Chen * \\ Center for Drug Design, College of Pharmacy, University of Minnesota, Minneapolis, MN 55455, USA; \\ rsotoaco@umn.edu (R.S.-A.); ejung@umn.edu (E.J.); liqiu2017@gmail.com (L.Q.); wils0125@umn.edu (D.J.W.) \\ * Correspondence: gerag012@umn.edu (R.J.G.); chenx462@umn.edu (L.C.)
}

\begin{abstract}
Discovery of compound $\mathbf{1}$ as a Zika virus (ZIKV) inhibitor has prompted us to investigate its $7 H$-pyrrolo[2,3-d]pyrimidine scaffold, revealing structural features that elicit antiviral activity. Furthermore, we have demonstrated that $9 \mathrm{H}$-purine or $1 \mathrm{H}$-pyrazolo[3,4-d]pyrimidine can serve as an alternative core structure. Overall, we have identified 4,7-disubstituted 7H-pyrrolo[2,3-d]pyrimidines and their analogs including compounds $\mathbf{1}, \mathbf{8}$ and $\mathbf{1 1}$ as promising antiviral agents against flaviviruses ZIKV and dengue virus (DENV). While the molecular target of these compounds is yet to be elucidated, 4,7-disubstituted 7H-pyrrolo[2,3-d]pyrimidines and their analogs are new chemotypes in the design of small molecules against flaviviruses, an important group of human pathogens.
\end{abstract}

Keywords: Zika virus; dengue virus; flavivirus; antiviral agents

Citation: Soto-Acosta, R.; Jung, E.; Qiu, L.; Wilson, D.J.; Geraghty, R.J.;

Chen, L. 4,7-Disubstituted

7H-Pyrrolo[2,3-d]pyrimidines and Their Analogs as Antiviral Agents against Zika Virus. Molecules 2021, 26, 3779. https://doi.org/10.3390/ molecules26133779

Academic Editor: Luděk Eyer

Received: 28 May 2021

Accepted: 18 June 2021

Published: 22 June 2021

Publisher's Note: MDPI stays neutral with regard to jurisdictional claims in published maps and institutional affiliations.

Copyright: (c) 2021 by the authors. Licensee MDPI, Basel, Switzerland. This article is an open access article distributed under the terms and conditions of the Creative Commons Attribution (CC BY) license (https:// creativecommons.org/licenses/by/ $4.0 /)$.

\section{Introduction}

The Flaviviruses are the largest genus in the Flaviviridae family and include well-known human pathogens such as dengue virus (DENV), West Nile virus (WNV), yellow fever virus (YFV), Japanese encephalitis virus (JEV) and Zika virus (ZIKV) [1]. DENV infects 390 million people, among whom 100 million exhibit disease symptoms, ranging from selflimiting dengue fever to life-threatening dengue hemorrhagic fever/shock syndrome [2]. DENV remains a focus of continued antiviral research, which has been bolstered by publicprivate partnerships. Promising direct-acting antiviral targets include E protein, NS2BNS3 (protease), NS4B and NS5 (RNA-dependent RNA polymerase, RdRp) [3-5]. Host factors that are important for viral replication or development of symptoms have also been explored [5]. While a number of promising anti-DENV agents have been tested in advanced preclinical or clinical studies, there are no specific antiviral therapeutics approved for DENV infection [6].

ZIKV has attracted public attention due to its global outbreaks and subsequent declaration as a global public health emergency by the World Health Organization (WHO) in 2016. While ZIKV infection usually causes no or mild symptoms, its association with severe neurological disorders, including microcephaly in newborn infants and Guillain-Barré syndrome in adults, has made ZIKV a global health concern [7]. The global epidemic of ZIKV and its devastating neurological complications have spurred ZIKV vaccine development and searches for small molecule anti-ZIKV therapeutics. Efforts have been devoted to targeting the ZIKV proteins, including NS2B-NS3 and NS5, facilitated by lessons learned from drug discovery in other Flaviviridae members, such as hepatitis $C$ virus (HCV), DENV and WNV [8-10]. Moreover, phenotypic screening of compound libraries and repurposing of approved drugs have been attractive approaches to discovering anti-ZIKV drugs [11], offering opportunities to identify previously unappreciated targets, particularly host factors. However, the recent rapid decline of ZIKV infection cases has led to an end to the emergency status and ZIKV has ceased to be a world-wide public health concern. Nonetheless, the current pandemic of coronavirus disease 2019 (COVID-19) has served as a warning that 
reemergence of ZIKV or emergence of ZIKV-like viruses cannot be excluded, calling for a continued search for novel antiviral strategies.

In our effort to discover antiviral agents against ZIKV, we screened our in-house compound library and identified compound 1 (Figure 1 and Table 1). Encouraged by its promising antiviral activity, we initiated a medicinal chemistry project to explore the substituents on positions 4 and 7 within compound 1's $7 H$-pyrrolo[2,3-d]pyrimidine scaffold, leading to analogs of excellent anti-ZIKV and -DENV activity. Here we report our structure-activity relationship (SAR) studies on compound $\mathbf{1}$ and evaluation of the resulting analogs in ZIKV and DENV.<smiles>O=[N+]([O-])c1ccc(Cn2ccc3c(NCc4cccc(Cl)c4)ncnc32)cc1</smiles><smiles>C#C[C@]1(O)[C@@H](O)[C@@H](CO)O[C@H]1n1cnc2c(N)ncnc21</smiles>

NITD008<smiles>Cc1cc(N)c2cc(NC(=O)Nc3ccc4nc(C)cc(N)c4c3)ccc2n1</smiles>

NSC 12155

1

Figure 1. Hit compound 1 and reference compounds.

Table 1. SAR study on ring A of the 7H-pyrrolo[2,3-d]pyrimidine scaffold against ZIKV.<smiles>[R]Cn1ccc2c(NCc3cccc(Cl)c3)ncnc21</smiles><smiles>c1ccc(CNc2ncnc3c2ccn3Cc2ccccc2)cc1</smiles>

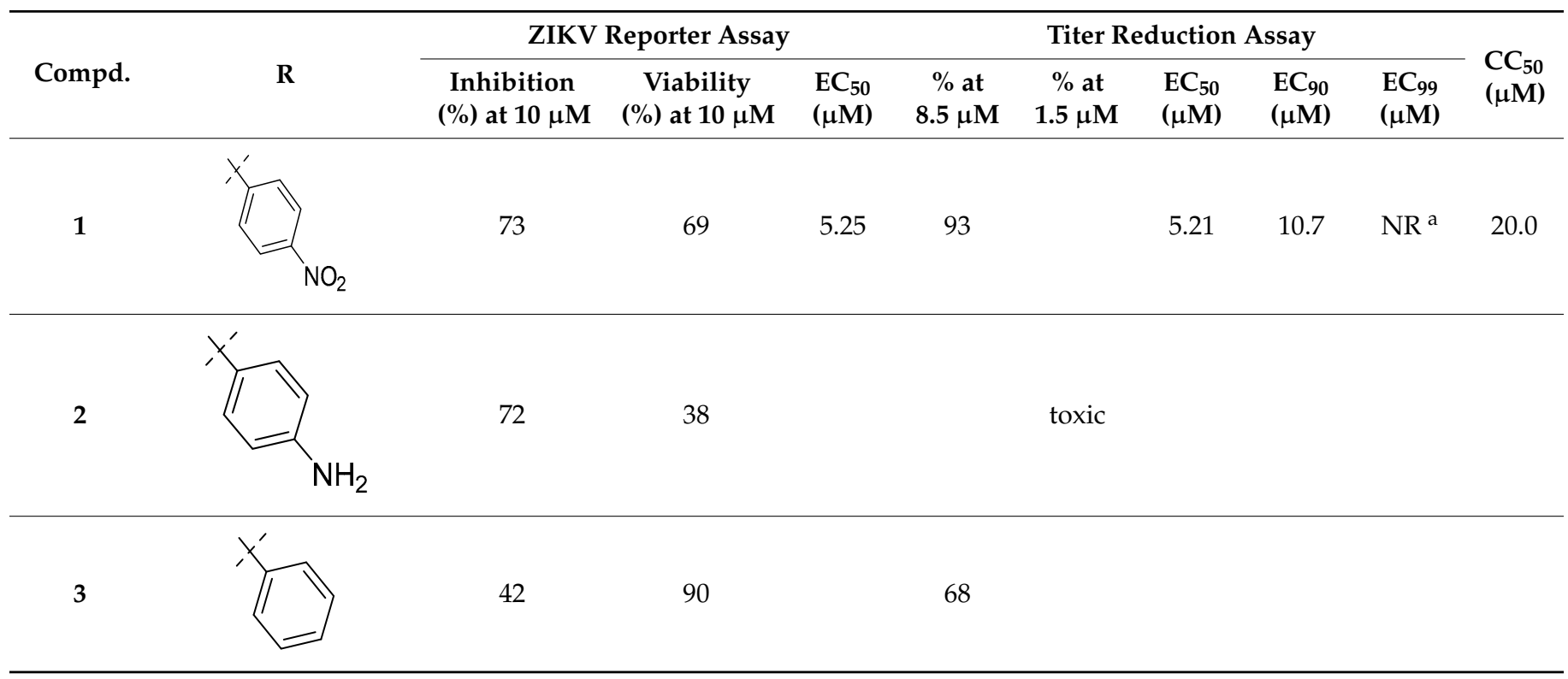


Table 1. Cont.

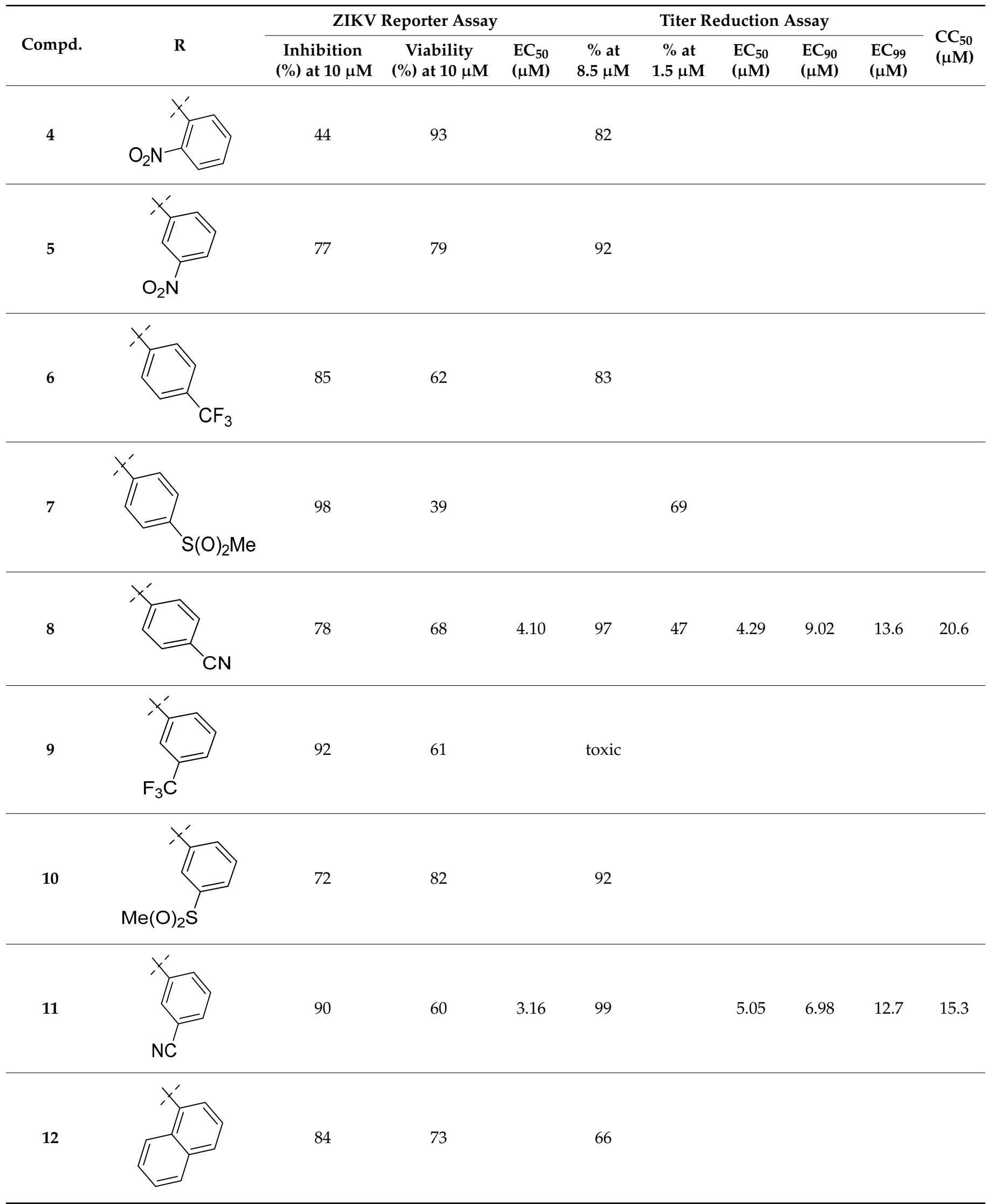


Table 1. Cont.

\begin{tabular}{|c|c|c|c|c|c|c|c|c|c|c|}
\hline \multirow[b]{2}{*}{ Compd. } & \multirow[b]{2}{*}{$\mathbf{R}$} & \multicolumn{3}{|c|}{ ZIKV Reporter Assay } & \multicolumn{5}{|c|}{ Titer Reduction Assay } & \multirow[b]{2}{*}{$\begin{array}{l}\mathrm{CC}_{50} \\
(\mu \mathrm{M})\end{array}$} \\
\hline & & $\begin{array}{l}\text { Inhibition } \\
(\%) \text { at } 10 \mu \mathrm{M}\end{array}$ & $\begin{array}{c}\text { Viability } \\
\text { (\%) at } 10 \mu \mathrm{M}\end{array}$ & $\begin{array}{l}\mathrm{EC}_{50} \\
(\mu \mathrm{M})\end{array}$ & $\begin{array}{c}\% \text { at } \\
8.5 \mu \mathrm{M}\end{array}$ & $\begin{array}{c}\% \text { at } \\
1.5 \mu \mathrm{M}\end{array}$ & $\begin{array}{l}\mathrm{EC}_{50} \\
(\mu \mathrm{M})\end{array}$ & $\begin{array}{l}\mathrm{EC}_{90} \\
(\mu \mathrm{M})\end{array}$ & $\begin{array}{l}\mathrm{EC}_{99} \\
(\mu \mathrm{M})\end{array}$ & \\
\hline 13 & & 75 & 45 & & & 18 & & & & \\
\hline 14 & & 100 & 48 & 0.93 & & 94 & 1.10 & 2.28 & $\mathrm{NR}^{\mathrm{a}}$ & 5.67 \\
\hline 15 & & 69 & 84 & & 0 & & & & & 39.6 \\
\hline 16 & & 95 & 34 & & & 10 & & & & \\
\hline DMSO & & 0 & 100 & & 0 & 0 & & & & \\
\hline $\begin{array}{l}\text { NITD008 } \\
(1 \mu \mathrm{M})\end{array}$ & & 100 & 100 & 0.14 & $\begin{array}{c}100 \\
\left(\mathrm{ND}^{\mathrm{b}}\right)\end{array}$ & & & & & $>45$ \\
\hline $\begin{array}{c}\text { NSC } \\
12155\end{array}$ & & 68 & 70 & 2.18 & 72 & 37 & 7.34 & 14.1 & $\mathrm{NR}^{\mathrm{a}}$ & 23.0 \\
\hline
\end{tabular}

${ }^{a} \mathrm{NR}$, not reached; ${ }^{\mathrm{b}} \mathrm{ND}$, no plaque detected.

\section{Results and Discussion}

To effectively search for ZIKV inhibitors, we constructed a luciferase-expressing ZIKV (see Supplemental Information) and established a ZIKV reporter assay. Using this assay, we screened our in-house compound library (at $10 \mu \mathrm{M})$ for anti-ZIKV activity along with NITD008 (Figure 1, at $1 \mu \mathrm{M}$ ) [12], a flavivirus RdRp inhibitor, and NSC 12155 (Figure 1, at $10 \mu \mathrm{M})$ [13], a flavivirus NS5 methyltransferase (MTase) inhibitor, as reference compounds. Gratifyingly, we identified compound 1, which possessed anti-ZIKV activity without drastically compromised cell viability (Table 1 ). Compound $\mathbf{1}^{\prime}$ EC $_{50}$ (reporter assay) and $\mathrm{CC}_{50}$ values were determined to be $5.25 \mu \mathrm{M}$ and $20.0 \mu \mathrm{M}$, respectively, highlighting good antiviral activity and relatively low cytotoxicity. As a result, compound $\mathbf{1}$ was evaluated in a titer-reduction assay, which revealed this compound's strong antiviral activity (93\% titer reduction) at $8.5 \mu \mathrm{M}$. Further dose-response analysis gave rise to an $\mathrm{EC}_{50}$ (titer-reduction) of $5.21 \mu \mathrm{M}$. These remarkable results suggested that compound 1 represented a promising chemical scaffold and warranted further SAR studies.

To guide our SAR studies, we established a general testing scheme. All newly synthesized compounds were first evaluated at $10 \mu \mathrm{M}$ in the ZIKV reporter assay and those that showed about $60 \%$ viability and about $60 \%$ inhibition were tested in the gold standard titer reduction assay at $8.5 \mu \mathrm{M}$ or at $1.5 \mu \mathrm{M}$ for those deemed toxic at $8.5 \mu \mathrm{M}$. If about 
$90 \%$ inhibition was reached in the titer-reduction assay, dose-response experiments were performed to determine $\mathrm{EC}_{50}$ (titer-reduction) values. For active compounds, $\mathrm{EC}_{50}$ in the reporter assay and $\mathrm{CC}_{50}$ were also measured.

Compound 1 contained a $7 H$-pyrrolo[2,3-d]pyrimidine core structure with substituents at positions 4 and 7. Our initial SAR study focused on ring A, which was located at position 7 (Table 1). Since the nitro group in compound 1 was an electron-withdrawing group, we first chose to reduce it to the corresponding aniline donned with an electron-donating property, giving rise to compound 2. It showed enhanced cytotoxicity in the reporter assay, a finding that was further supported by the toxicity seen in the titer-reduction assay. Second, we prepared compound 3 with no substituents on ring A. While compound 3 was less toxic, the antiviral activity was also diminished. These two modifications suggested that an electron-withdrawing group like nitro was beneficial. As a result, we synthesized compounds 4 and 5, in which a nitro group was placed at the ortho and meta positions, respectively. While compound 4 was less active, compound 5 exhibited antiviral activity comparable to those of compound $\mathbf{1}$ in both assays, suggesting that the meta position was another feasible modification site. After identifying these two potential modification sites, we proceeded to prepare compounds 6-8 and 9-11. In compounds 6-8, an electronwithdrawing group including trifluoromethyl, methylsufonyl, and cyano, respectively, was placed at the para position while in $\mathbf{9 - 1 1}$ an electron-withdrawing group was appended at the meta position. Evaluation of these compounds revealed that an electron-withdrawing group at either the para or meta position generally led to good anti-ZIKV activity at levels in line with that of compound $\mathbf{1}$. Specifically, compounds $\mathbf{8}$ and 11, in which a cyano group was used, exhibited excellent antiviral ability in the titer reduction assay. Both compounds possessed an $\mathrm{EC}_{99}$ value of about $13 \mu \mathrm{M}$ even though compound 11 was slightly more toxic than compound 8 as judged by their $\mathrm{CC}_{50}$ values. Taken together, these results showed that introducing a simple electron-withdrawing group, preferably nitro and cyano, at the para or meta position led to excellent anti-ZIKV activity, especially in terms of titer-reducing capability. Therefore, a further structural exploration of ring A was justified.

We next investigated fused and heterocyclic rings by preparing and testing compounds 12-16. Replacement of the phenyl ring in compound 1 with a 1-naphthyl or 2-naphthyl ring as seen in compound $\mathbf{1 2}$ or $\mathbf{1 3}$ led to diminished antiviral activity. Compound 14, in which a quinolone ring was used to take advantage of its electron-deficient nature, exerted complete inhibition $\left(\mathrm{EC}_{50}=0.93 \mu \mathrm{M}\right)$ but showed high cytotoxicity when tested at $10 \mu \mathrm{M}$ in the ZIKV reporter assay. To accurately assess the activity of compound 14, it was tested at lower concentrations in the titer-reduction assay, by which the $\mathrm{EC}_{90}$ value was determined to be $2.28 \mu \mathrm{M}$. Given the fact that compound 14 has a $\mathrm{CC}_{50}$ value of $5.67 \mu \mathrm{M}$, its therapeutic window was relatively narrow. We also attempted to merge multiple structural features. For instance, a naphthyl ring was combined with a cyano group in compound $\mathbf{1 5}$ while a quinolone ring was used in conjunction with a chloro group in 16. Unfortunately, these two compounds displayed negligible titer-reducing capability even though they had good activity in the reporter assay. Taken together, our exploration of fused and heterocyclic rings resulted in no significant improvement in antiviral activity.

After examination of ring $A$, we proceeded to study ring $B$ at position 4 by synthesizing two groups of compounds (Table 2). Because the para-nitrobenzyl moiety in compound 1 had been proved to be one of the best substituents, it was retained in the first groups (compounds 17-24) and variation of ring B was then explored. First, we prepared compound 17, which had no substitution at position 4 of the $7 \mathrm{H}$-pyrrolo[2,3-d]pyrimidine core. Compound $17^{\prime}$ 's lack of antiviral activity clearly demonstrated that a substituent at position 4 was needed. A simple benzyl substituent in compound $\mathbf{1 8}$ resulted in higher toxicity when compared with compound $\mathbf{1}$, suggesting that substitution on the phenyl was preferred. Accordingly, a chloro group at the ortho position was explored and the resulting compound 19 showed activity comparable to that of compound $\mathbf{1}$. On the other hand, a para-chloro group in 20 gave rise to higher cytotoxicity. A combination of two chloro groups placed at different positions was also examined. Among the resultant compounds 21-23, 23 exhibited high 
anti-ZIKV activity not only in the reporter $\left(\mathrm{EC}_{50}=5.70 \mu \mathrm{M}\right)$ but also in the titer-reduction assay. Notably, it achieved a three-log titer reduction $\left(\mathrm{EC}_{99.9}=12.3 \mu \mathrm{M}\right.$, footnote of Table 2$)$ and had an $\mathrm{CC}_{50}$ value of $26.8 \mu \mathrm{M}$. These parameters were slightly better than those of compound 8, one of the best inhibitors. However, use of a 1-naphthyl ring in compound 24 failed to improve antiviral activity. We also investigated another group of compounds 25-28, in which a para-cyanobenzyl moiety as seen in compound $\mathbf{8}$ was adopted at position 7 and variation of ring B was studied. When the chloro group in compound 8 was replaced with an electron-donating methyl group, the resulting compound 25 was more toxic than compound 8, suggesting that an electron-withdrawing group was desirable. Compounds 26-28, in which chloro groups at different positions were combined, showed no significant enhancement of antiviral activity. Collectively, these structural modifications showed that a position 4 substitution was needed and electron-withdrawing group(s) on the phenyl ring were desired for anti-ZIKV property.

Table 2. SAR study on ring B of the 7H-pyrrolo[2,3-d]pyrimidine scaffold against ZIKV.<smiles>Nc1ncnc2c1ccn2Cc1ccc([N+](=O)[O-])cc1</smiles>

17<smiles>[R]CNc1ncnc2c1ccn2Cc1ccc([R])cc1</smiles><smiles>[Te]c1ncnc2c1ccn2CC1CCCCCCC1</smiles>

18-28

\begin{tabular}{|c|c|c|c|c|c|c|c|c|c|c|}
\hline \multirow[b]{2}{*}{ Compd. } & \multirow[b]{2}{*}{$\mathbf{R}^{1}$} & \multirow[b]{2}{*}{$\mathbf{R}^{2}$} & \multicolumn{3}{|c|}{ ZIKV Reporter Assay } & \multicolumn{5}{|c|}{ Titer Reduction Assay } \\
\hline & & & $\begin{array}{c}\text { Inhibition (\%) } \\
\text { at } 10 \mu \mathrm{M}\end{array}$ & $\begin{array}{c}\text { Viability (\%) } \\
\text { at } 10 \mu \mathrm{M}\end{array}$ & $\begin{array}{l}\mathrm{EC}_{50} \\
(\mu \mathrm{M})\end{array}$ & $\begin{array}{c}\% \text { at } \\
8.5 \mu \mathrm{M}\end{array}$ & $\begin{array}{c}\% \text { at } \\
1.5 \mu \mathrm{M}\end{array}$ & $\begin{array}{l}\mathrm{EC}_{50} \\
(\mu \mathrm{M})\end{array}$ & $\begin{array}{l}\mathrm{EC}_{90} \\
(\mu \mathrm{M})\end{array}$ & $\begin{array}{l}\mathrm{EC}_{99} \\
(\mu \mathrm{M})\end{array}$ \\
\hline
\end{tabular}

\begin{tabular}{lllll}
\hline 17 & $\mathrm{NA}^{\mathrm{a}}$ & $\mathrm{NA}^{\mathrm{a}}$ & 0 & 92 \\
\hline $\mathbf{1 8}$ & $\mathrm{NO}_{2}$ & 96 & 42 \\
\hline
\end{tabular}

$19 \quad \mathrm{NO}_{2}$<smiles>CC(C)(C)c1ccccc1Cl</smiles><smiles>CC(C)(C)c1ccc(Cl)cc1</smiles><smiles>CC(C)(C)c1cccc(Cl)c1Cl</smiles> 
Table 2. Cont.

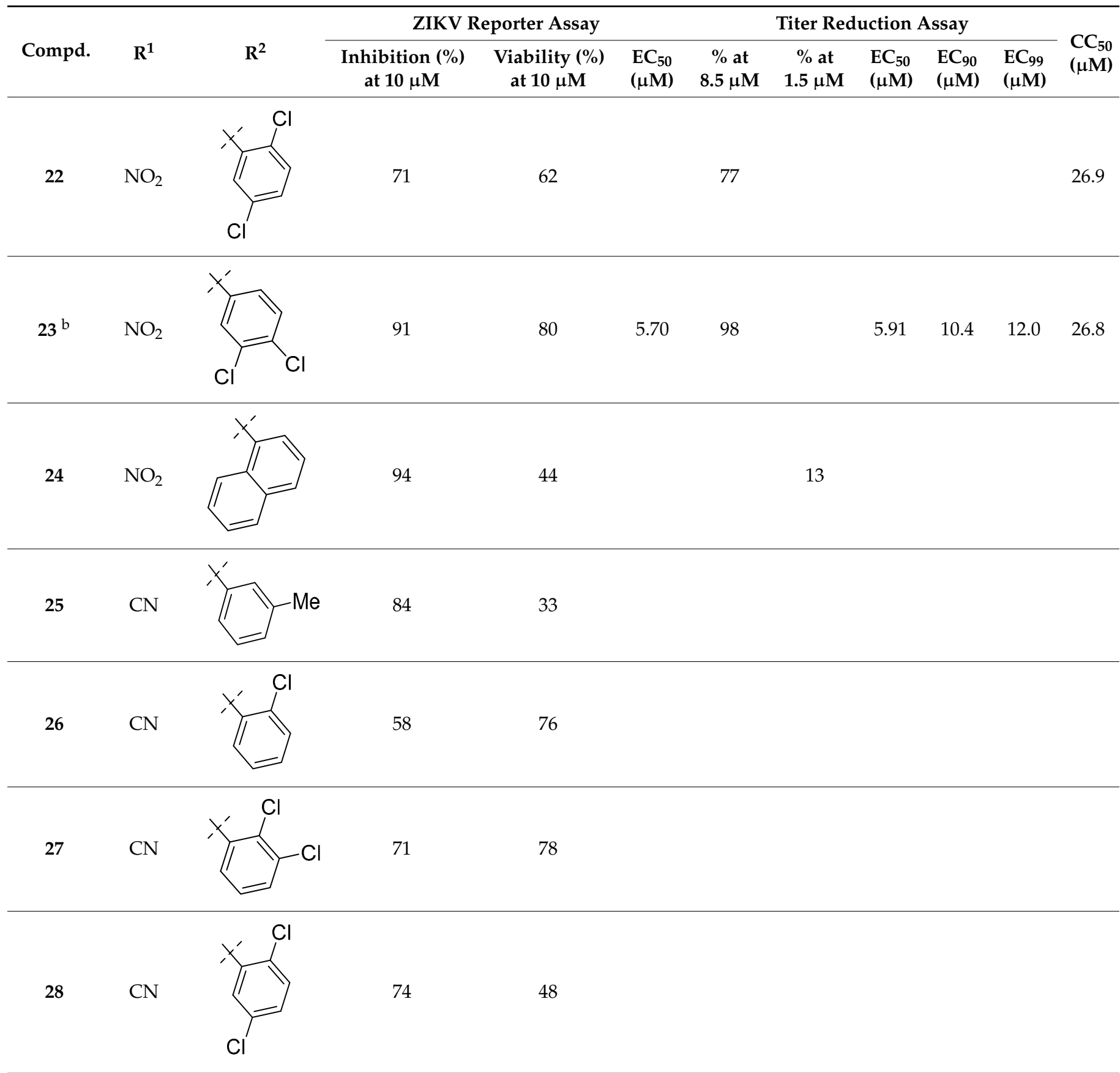

${ }^{\mathrm{a}} \mathrm{NA}$, not applicable; ${ }^{\mathrm{b}} \mathrm{EC}_{99.9}=12.3 \mu \mathrm{M}$ in the titer reduction assay.

Besides the 7H-pyrrolo[2,3-d]pyrimidine scaffold, we also investigated $9 \mathrm{H}$-purine (29 and 30) and 1H-pyrazolo[3,4-d]pyrimidine (31 and 32) as a potential core structure (Table 3). Since a para-nitro or -cyanobenzyl substituent in combination with a metachlorobenzylamine elicited high antiviral activity, they were retained in our new study. Compared with active inhibitors that contained a $7 \mathrm{H}$-pyrrolo[2,3-d]pyrimidine core, new compounds appeared to be generally less toxic and possessed similar anti-ZIKV activity in the reporter assay. Also importantly, they exhibited good to excellent titer-reducing capacity. Among these compounds, 30 had an $\mathrm{EC}_{90}$ value of $12.4 \mu \mathrm{M}$ in the titer reduction assay and a CC 50 value of $49.3 \mu \mathrm{M}$, indicative of its excellent activity and relatively low cytotoxicity. Taken together, these results suggested that $9 \mathrm{H}$-purine and $1 \mathrm{H}$-pyrazolo[3,4-d]pyrimidine were viable replacements of the $7 \mathrm{H}$-pyrrolo[2,3-d]pyrimidine scaffold. 
Table 3. SAR study on the scaffold replacement against ZIKV.<smiles>[R]c1ccc(Cn2cnc3c(NCc4cccc(Cl)c4)ncnc32)cc1</smiles>

$29-30$<smiles>[R]c1ccc(Cn2ncc3c(NCc4cccc(Cl)c4)ncnc32)cc1</smiles>

$31-32$

\begin{tabular}{|c|c|c|c|c|c|c|c|c|c|c|}
\hline \multirow[b]{2}{*}{ Compd. } & \multirow[b]{2}{*}{$\mathbf{R}$} & \multicolumn{3}{|c|}{ ZIKV Reporter Assay } & \multicolumn{5}{|c|}{ Titer Reduction Assay } & \multirow{2}{*}{$\begin{array}{l}C_{50} C_{50} \\
(\mu M)\end{array}$} \\
\hline & & $\begin{array}{l}\text { Inhibition } \\
(\%) \text { at } 10 \mu \mathrm{M}\end{array}$ & $\begin{array}{c}\text { Viability (\%) } \\
\text { at } 10 \mu \mathrm{M}\end{array}$ & $\begin{array}{l}\mathrm{EC}_{50} \\
(\mu \mathrm{M})\end{array}$ & $\begin{array}{c}\% \text { at } \\
8.5 \mu \mathrm{M}\end{array}$ & $\begin{array}{c}\% \text { at } \\
1.5 \mu \mathrm{M}\end{array}$ & $\begin{array}{l}\mathrm{EC}_{50} \\
(\mu \mathrm{M})\end{array}$ & $\begin{array}{l}\mathrm{EC}_{90} \\
(\mu \mathrm{M})\end{array}$ & $\begin{array}{l}\mathrm{EC}_{99} \\
(\mu \mathrm{M})\end{array}$ & \\
\hline 29 & $\mathrm{NO}_{2}$ & 59 & 87 & & 90 & & & & & 24.5 \\
\hline 30 & $\mathrm{CN}$ & 68 & 94 & & 93 & & 7.12 & 12.4 & $\mathrm{NR}^{\mathrm{a}}$ & 49.3 \\
\hline 31 & $\mathrm{NO}_{2}$ & 83 & 96 & & 86 & & & & & \\
\hline 32 & $\mathrm{CN}$ & 79 & 88 & & 88 & & & & & 17.4 \\
\hline
\end{tabular}

Encouraged by the high antiviral activity exhibited by the 4,7-disubstituted $7 \mathrm{H}$ pyrrolo[2,3-d]pyrimidines and their analogs, selected compounds were also tested against DENV-2 with NITD008 $(1 \mu \mathrm{M})$ and NSC12155 $(8.5 \mu \mathrm{M})$ as reference inhibitors (Figure 2). Compounds were tested at $8.5 \mu \mathrm{M}$ except for compound 14, which was used at $1.5 \mu \mathrm{M}$. All selected inhibitors showed higher anti-DENV activity than the reference NSC12155 and several compounds offered $>90 \%$ protection against DENV. Interestingly, among the top inhibitors were compounds 1, 8, 11 and 23, which also exhibited the highest antiviral activity in ZIKV. These preliminary results suggested that the 4,7-disubstituted 7H-pyrrolo[2,3d]pyrimidines and their analogs could represent a new class of antiviral agents against flaviviruses and they might work through a common mechanism of action.

The syntheses of 4,7-disubstituted 7H-pyrrolo[2,3-d]pyrimidines and their analogs were straightforward (Scheme 1). To study the effect of ring $\mathrm{A}$ attached to the $7 \mathrm{H}$ pyrrolo[2,3-d]pyrimidine core structure, alkylation $\left(\mathrm{K}_{2} \mathrm{CO}_{3}\right.$ in $\left.\mathrm{CH}_{3} \mathrm{CN}\right)$ of $7 \mathrm{H}$-pyrrolo[2,3d]pyrimidine (33) was accomplished generally without column purification to give chlorides $34 \mathbf{a}-\mathbf{0}$, which were subsequently treated with 3-chlorobenzylamine to afford compounds 1 and 3-16 in excellent yields. Reduction of the nitro group in compound 1 with $\mathrm{SnCl}_{2}$ gave 2 . To study the effect of ring $\mathrm{B}$, chloride $34 \mathrm{a}$ underwent aminolysis to afford compound 17 while intermediate $34 \mathrm{a}$ and $\mathbf{3 4 \mathrm { g }}$ were treated with various amines to furnish compounds 18-24 and 25-28, respectively. To investigate the effect of scaffold replacement, 6-chloropurine (35) was alkylated under the same conditions as those that were used for 33. When 35 was $N$-alkylated with 4-nitrobenzyl bromide, the $N 9$ alkylated isomer 36a [14] was isolated in $61 \%$ yield. This regioisomer was confirmed by a combination of ${ }^{1} \mathrm{H}-{ }^{13} \mathrm{C}$ heteronuclear multiple quantum correlation (HMQC) and heteronuclear multiple bond correlation spectroscopy (HMBC) (Figure S2). Similarly, chloride 36b [15] was obtained as an N9-alkylated isomer in the presence of $\mathrm{K}_{2} \mathrm{CO}_{3}$. In contrast, different conditions $\left(\mathrm{Et}_{3} \mathrm{~N}\right.$ in $\mathrm{DMF}$ ) were needed to ensure successful alkylation of 4-chloropyrazolo[3,4-d]pyrimidine (37) to give chlorides 38a and 38b, whose N1 substitution was also established by HMBC experiments. Upon treatment with 3-chlorobenzylamine, the resulting chlorides $36 \mathbf{a}-\mathbf{b}$ and 38a-b, were converted into purines 29-30 and pyrazolo[3,4-d]pyrimidines 31-32, respectively. The substitution pattern of these regioisomers was further confirmed by a combination of HMQC and HMBC with compound 29 shown as an example in Figure S3. 


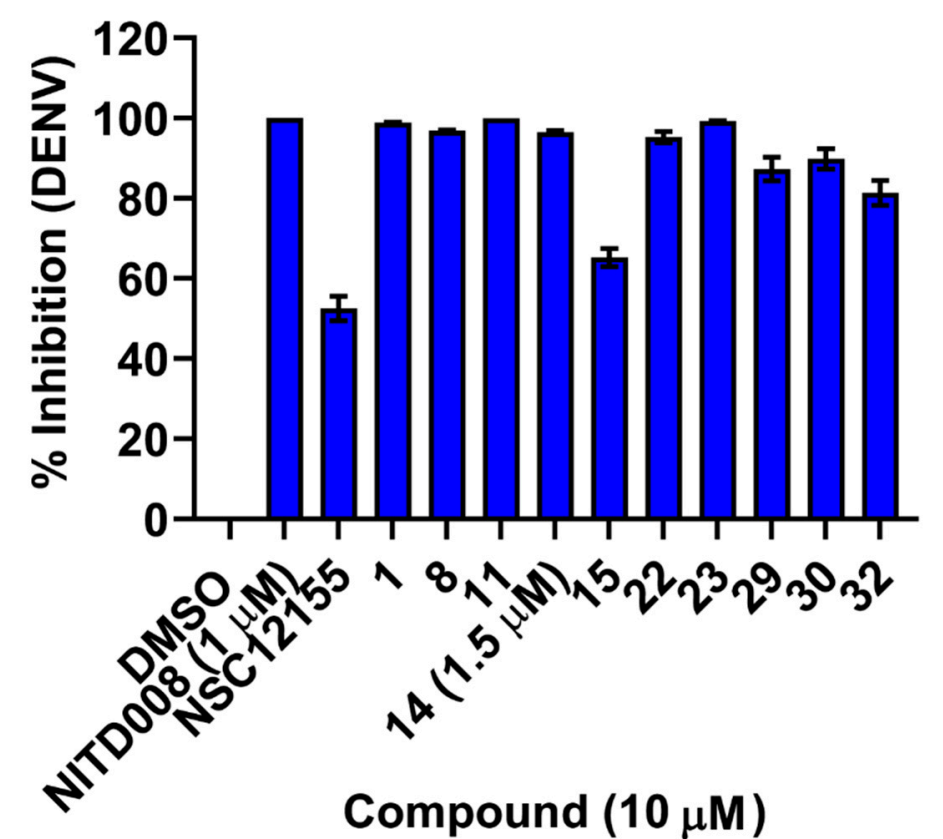

Figure 2. Inhibition of DENV by selected compounds. Huh7 cells were plated in 24 well plate. Next day, cells were inoculated with DENV (MOI =0.05). After $2 \mathrm{~h}$ of infection inoculum was retired and the cells were treated with inhibitors at $8.5 \mu \mathrm{M}$ (except for compound 14, $1.5 \mu \mathrm{M}$ ) for $72 \mathrm{~h}$. Next, supernatants were assayed for viral titer by plaque assay and titers were normalized vs DMSO and expressed as \% inhibition. The experiment was performed two independent times and each sample was performed in triplicate. The bars depict mean plus standard error of the mean.

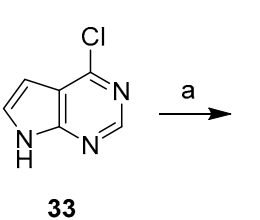

33<smiles>[R]Cn1ccc2c(Cl)ncnc21</smiles>

$34 a-0$<smiles>[R]Cn1ccc2c(NCc3cccc(Cl)c3)ncnc21</smiles>

1, 3-16

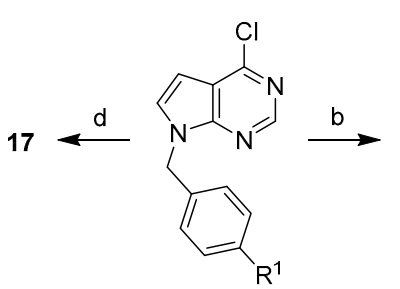

34a, $\mathrm{R}^{1}=\mathrm{NO}_{2}$ $34 \mathrm{~g}, \mathrm{R}^{1}=\mathrm{CN}$

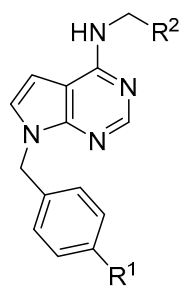

18-24, $\mathrm{R}^{1}=\mathrm{NO}_{2}$ 25-28, $R^{1}=C N$

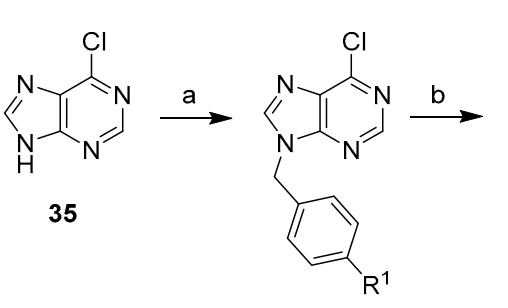

36a, $\mathrm{R}^{1}=\mathrm{NO}_{2}$ $36 \mathrm{~b}, \mathrm{R}^{1}=\mathrm{CN}$<smiles>Clc1cccc(CNc2ncnc3c2ncn3Cc2ccccc2)c1</smiles>

29, $\mathrm{R}^{1}=\mathrm{NO}_{2}$ $30, \mathrm{R}^{1}=\mathrm{CN}$

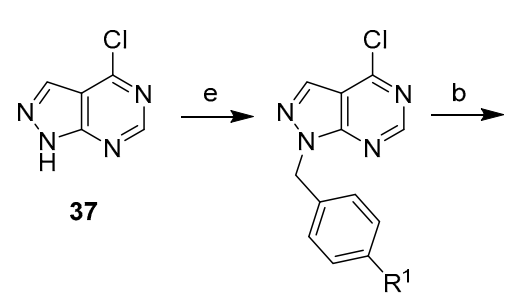

38a, $\mathrm{R}^{1}=\mathrm{NO}_{2}$ $38 \mathrm{~b}, \mathrm{R}^{1}=\mathrm{CN}$

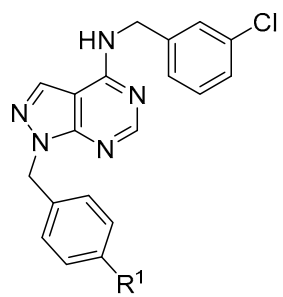

31, $\mathrm{R}^{1}=\mathrm{NO}_{2}$

$32, \mathrm{R}^{1}=\mathrm{CN}$

Scheme 1. Syntheses of 4,7-disubstituted 7H-pyrrolo[2,3-d]pyrimidines and their analogs. Reagents and conditions: (a) bromides, $\mathrm{K}_{2} \mathrm{CO}_{3}, \mathrm{CH}_{3} \mathrm{CN}$, rt; (b) amines, DIPEA, 2-methoxyethan-1-ol, $100{ }^{\circ} \mathrm{C}$; (c) $\mathrm{SnCl}_{2}, \mathrm{EtOH}, 70{ }^{\circ} \mathrm{C}$; (d) $\mathrm{NH}_{3}, \mathrm{H}_{2} \mathrm{O}$, 1,4-dioxane, $120^{\circ} \mathrm{C}$; (e) bromides, $\mathrm{Et}_{3} \mathrm{~N}, \mathrm{DMF}$, rt.

\section{Conclusions}

Identification of compound $\mathbf{1}$ as an anti-ZIKV agent has prompted us to investigate its $7 H$-pyrrolo[2,3-d]pyrimidine core structure, leading to several inhibitors including compounds 1, 8 and 11 that possess promising anti-ZIKV activity, especially in the gold standard 
titer-reduction assay. Our SAR studies have revealed that rings A and B at positions 7 and 4, respectively, are desired. For ring A, while fused and heterocyclic rings can be tolerated, a phenyl ring decorated with an electron-withdrawing group, preferably nitro and cyano, at the para or meta position gives rise to excellent titer-reducing capability in ZIKV. For ring B, electron-withdrawing group(s) on a phenyl ring are also preferred. However, we have not been able to identify an optimal combination of electron-withdrawing groups. This could be due to the limited scope of electron-withdrawing groups explored in the current study. Furthermore, we have demonstrated that $9 \mathrm{H}$-purine or $1 \mathrm{H}$-pyrazolo[3,4-d]pyrimidine can serve as an alternative scaffold, generally leading to reduced cytotoxicity. We propose a general pharmacophore model in which the central $7 \mathrm{H}$-pyrrolo[2,3-d]pyrimidine ring organizes rings $\mathrm{A}$ and $\mathrm{B}$ (preferably donned with electro-withdrawing groups) into an orientation that elicits antiviral activity. In addition, $7 \mathrm{H}$-pyrrolo[2,3-d]pyrimidine can be replaced by $9 H$-purine or $1 H$-pyrazolo[3,4-d]pyrimidine, which supports a future study on scaffold-hopping. Furthermore, selected compounds also inhibit DENV-2. To our best knowledge, no similar compounds built on a $7 \mathrm{H}$-pyrrolo[2,3-d]pyrimidine, $9 \mathrm{H}$ purine, or $1 H$-pyrazolo[3,4-d]pyrimidine core structure has been reported as flavivirus inhibitors. Therefore, 4,7-disubstituted 7H-pyrrolo[2,3-d]pyrimidines and their analogs hold promise as new chemotypes in the design of antiviral agents against flaviviruses, an important group of human pathogens. Nonetheless, the compounds we have discovered suffer from relatively low therapeutic indices, a critical issue that will be addressed in our future studies.

The molecular target of these antiviral agents is yet to be elucidated. One possible viral target is the ZIKV NS5 MTase, which is required for generating the type $\mathrm{I}^{\prime}$ cap through sequential $N 7$ and $2^{\prime}-O$ methylation of the viral RNA cap using $S$-adenosylmethionine as a methyl donor and releasing $S$-adenosylhomocysteine as a byproduct. Studies have shown that $N 7$ methylation is crucial for viral replication $[16,17]$ and $2 '-O$ methylation helps viruses evade the host innate immune response.[18] Unfortunately, compound 1 was inactive $\left(\mathrm{IC}_{50}>100 \mu \mathrm{M}\right)$ against ZIKV NS5 MTase in our biochemical assay, suggesting that NS5 MTase was unlikely the molecular target of these antiviral compounds. It is also possible that they target a host factor that is essential for virus replication. While identifying the target of a small molecule remains challenging, activity-based protein profiling (ABPP) [19] holds promise because it offers an unbiased approach to identify the molecular target of a wide range of small molecules [20-22]. ABPP requires design and synthesis of an ABPP probe, a task that will be facilitated by our experience[23] with this proteomic approach and the SAR information obtained from the current study. In summary, 4,7-disubstituted 7H-pyrrolo[2,3-d]pyrimidines and their analogs are promising antiviral agents against flaviviruses ZIKV and DENV. Further exploration of the core structures and appended rings and elucidation of the molecular target are warranted.

\section{Experimental Section}

\subsection{General Procedures}

All commercial reagents were used as provided unless otherwise indicated. An anhydrous solvent dispensing system (J. C. Meyer, Laguna Beach, CA, USA) using two packed columns of neutral alumina was used for drying THF, Et $t_{2} \mathrm{O}$, and $\mathrm{CH}_{2} \mathrm{Cl}_{2}$, whereas two packed columns of molecular sieves were used to dry DMF. Solvents were dispensed under argon. Flash chromatography was performed with RediSep $\mathrm{R}_{\mathrm{f}}$ silica gel columns (Teledyne ISCO, Lincoln, NE, USA) on a CombiFlash ${ }^{\circledR} R_{\mathrm{f}}$ system (Teledyne ISCO, Lincoln, NE, USA) using the solvents as indicated. Nuclear magnetic resonance spectra were recorded on a Varian $600 \mathrm{MHz}$ (Palo Alto, CA, USA) or Bruker $400 \mathrm{MHz}$ (Billerica, MA, USA) spectrometer with $\mathrm{Me}_{4} \mathrm{Si}$ or signals from residual solvent as the internal standard for ${ }^{1} \mathrm{H}$ or ${ }^{13} \mathrm{C}$. Chemical shifts are reported in ppm, and signals are described as s (singlet), d (doublet), $\mathrm{t}$ (triplet), q (quartet), m (multiplet), br s (broad singlet), and dd (double doublet). Values given for coupling constants are first order. High resolution mass spectra were recorded on 
an TOF II TOF/MS instrument (Agilent, Santa Clara, CA, USA) equipped with either an ESI or APCI interface at the University of Minnesota Center for Drug Design.

\subsection{Chemistry}

4-Chloro-7-(4-nitrobenzyl)-7H-pyrrolo[2,3-d]pyrimidine (34a). To a suspension of 4-chloro-7Hpyrrolo[2,3-d]pyrimidine $(33,614 \mathrm{mg}, 4.00 \mathrm{mmol})$ in anhydrous $\mathrm{CH}_{3} \mathrm{CN}(40 \mathrm{~mL})$ were added $\mathrm{K}_{2} \mathrm{CO}_{3}(1.67 \mathrm{~g}, 12.1 \mathrm{mmol})$ and 4-nitrobenzyl bromide $(1.04 \mathrm{~g}, 4.81 \mathrm{mmol})$. The resulting mixture was allowed to stir at $\mathrm{rt}$ for $20 \mathrm{~h}$ and concentrated. The residue was suspended in $\mathrm{MeOH}(20 \mathrm{~mL})$ and poured into stirring water $(120 \mathrm{~mL})$. The precipitate was filtered, washed with water and hexanes, dried in vacuo to give compound 34a as a pale fluffy solid (1.11 g, 96\%). ${ }^{1} \mathrm{H}-\mathrm{NMR}\left(400 \mathrm{MHz}, \mathrm{CDCl}_{3}\right) \delta 8.67(\mathrm{~s}, 1 \mathrm{H}), 8.18(\mathrm{~d}, J=8.7 \mathrm{~Hz}$, $2 \mathrm{H}), 7.35(\mathrm{~d}, J=8.7 \mathrm{~Hz}, 2 \mathrm{H}), 7.24(\mathrm{~d}, J=3.6 \mathrm{~Hz}, 1 \mathrm{H}), 6.69(\mathrm{~d}, J=3.6 \mathrm{~Hz}, 1 \mathrm{H}), 5.57(\mathrm{~s}, 2 \mathrm{H})$; ${ }^{13} \mathrm{C}-\mathrm{NMR}\left(100 \mathrm{MHz}, \mathrm{CDCl}_{3}\right) \delta 152.8,151.4,151.3,147.9,143.6,128.9,128.3,124.4,117.7$, 100.9, 48.0. HRMS (ESI ${ }^{+}$) $m / z$ calcd. for $\mathrm{C}_{13} \mathrm{H}_{10} \mathrm{ClN}_{4} \mathrm{O}_{2}[\mathrm{M}+\mathrm{H}]^{+} 289.0487$, found 289.0487 .

7-Benzyl-4-chloro-7H-pyrrolo[2,3-d]pyrimidine (34b). Compound $\mathbf{3 4 \mathbf { b }}$ was prepared from 33 $(154 \mathrm{mg}, 1.00 \mathrm{mmol})$ and benzyl bromide $(143 \mu \mathrm{L}, 1.20 \mathrm{mmol})$ in a fashion similar to the one described for compound 34a [24]. Brownish syrup, $251 \mathrm{mg}$, quantitative yield. ${ }^{1} \mathrm{H}-\mathrm{NMR}$ $\left(400 \mathrm{MHz}, \mathrm{CDCl}_{3}\right) \delta 8.72(\mathrm{~s}, 1 \mathrm{H}), 7.34-7.22(\mathrm{~m}, 6 \mathrm{H}), 6.66(\mathrm{~d}, J=3.6 \mathrm{~Hz}, 1 \mathrm{H}), 5.48(\mathrm{~s}, 2 \mathrm{H})$; ${ }^{13} \mathrm{C}-\mathrm{NMR}\left(100 \mathrm{MHz}, \mathrm{CDCl}_{3}\right) \delta 151.0,149.7,145.1,135.9,130.2,129.1,128.4,127.8,117.5$, 100.5, 48.8. HRMS $\left(\mathrm{ESI}^{+}\right) \mathrm{m} / z$ calcd. for $\mathrm{C}_{13} \mathrm{H}_{11} \mathrm{ClN}_{3}[\mathrm{M}+\mathrm{H}]^{+} 244.0636$, found 244.0636.

4-Chloro-7-(2-nitrobenzyl)-7H-pyrrolo[2,3-d]pyrimidine (34c). Compound 34c was prepared from $33(154 \mathrm{mg}, 1.00 \mathrm{mmol})$ and 2-nitrobenzyl bromide $(260 \mathrm{mg}, 1.20 \mathrm{mmol})$ in a fashion similar to the one described for compound 34a. Yellowish solid, $280 \mathrm{mg}$, yield $97 \% .{ }^{1} \mathrm{H}-$ $\operatorname{NMR}\left(400 \mathrm{MHz}, \mathrm{CDCl}_{3}\right) \delta 8.63(\mathrm{~s}, 1 \mathrm{H}), 8.15(\mathrm{dd}, J=8.0,1.2 \mathrm{~Hz}, 1 \mathrm{H}), 7.53-7.47(\mathrm{~m}, 2 \mathrm{H})$, $7.33(\mathrm{~d}, J=3.6 \mathrm{~Hz}, 1 \mathrm{H}), 6.86(\mathrm{dd}, J=7.8,1.2 \mathrm{~Hz}, 1 \mathrm{H}), 6.71(\mathrm{~d}, J=3.6 \mathrm{~Hz}, 1 \mathrm{H}), 5.49(\mathrm{~s}, 2 \mathrm{H})$; ${ }^{13} \mathrm{C}-\mathrm{NMR}\left(100 \mathrm{MHz}, \mathrm{CDCl}_{3}\right) \delta 152.7,151.6,151.3,147.7,134.3,132.4,129.7,129.4,129.2$, 125.6, 117.8, 100.7, 46.0. HRMS (ESI $\left.{ }^{+}\right) \mathrm{m} / z$ calcd. for $\mathrm{C}_{13} \mathrm{H}_{10} \mathrm{ClN}_{4} \mathrm{O}_{2}[\mathrm{M}+\mathrm{H}]^{+} 289.0487$, found 289.0487 .

4-Chloro-7-(3-nitrobenzyl)-7H-pyrrolo[2,3-d]pyrimidine (34d). Compound 34d was prepared from $33(154 \mathrm{mg}, 1.00 \mathrm{mmol})$ and 3-nitrobenzyl bromide $(260 \mathrm{mg}, 1.20 \mathrm{mmol})$ in a fashion similar to the one described for compound 34a. Yellowish solid, $266 \mathrm{mg}$, yield $92 \% .{ }^{1} \mathrm{H}-$ $\operatorname{NMR}\left(400 \mathrm{MHz}, \mathrm{CDCl}_{3}\right) \delta 8.67(\mathrm{~s}, 1 \mathrm{H}), 8.16(\mathrm{dd}, \mathrm{J}=7.5,1.8 \mathrm{~Hz}, 1 \mathrm{H}), 8.11(\mathrm{~s}, 1 \mathrm{H}), 7.56-7.49$ $(\mathrm{m}, 2 \mathrm{H}), 7.26(\mathrm{~d}, \mathrm{~J}=3.6 \mathrm{~Hz}, 1 \mathrm{H}), 6.69(\mathrm{~d}, \mathrm{~J}=3.6 \mathrm{~Hz}, 1 \mathrm{H}), 5.57(\mathrm{~s}, 2 \mathrm{H}) ;{ }^{13} \mathrm{C}-\mathrm{NMR}(100 \mathrm{MHz}$, $\left.\mathrm{CDCl}_{3}\right) \delta 152.7,151.3(\times 2), 148.7,138.6,133.7,130.2,128.8,123.4,122.6,117.7,100.9,47.9$. HRMS (ESI ${ }^{+}$) $m / z$ calcd for $\mathrm{C}_{13} \mathrm{H}_{10} \mathrm{ClN}_{4} \mathrm{O}_{2}[\mathrm{M}+\mathrm{H}]^{+} 289.0487$, found 289.0487.

4-Chloro-7-(4-(trifluoromethyl)benzyl)-7H-pyrrolo[2,3-d]pyrimidine (34e). Compound 34e was prepared from $33(154 \mathrm{mg}, 1.00 \mathrm{mmol})$ and 4-trifluoromethylbenzyl bromide (288 $\mathrm{mg}$, $1.20 \mathrm{mmol}$ ) in a fashion similar to the one described for compound 34a [24]. Pale solid, $307 \mathrm{mg}$, yield 98\%. ${ }^{1} \mathrm{H}-\mathrm{NMR}\left(400 \mathrm{MHz}, \mathrm{CDCl}_{3}\right) \delta 8.67(\mathrm{~s}, 1 \mathrm{H}), 7.59(\mathrm{~d}, J=8.4 \mathrm{~Hz}, 2 \mathrm{H}), 7.31$ $(\mathrm{d}, J=8.4 \mathrm{~Hz}, 2 \mathrm{H}), 7.22(\mathrm{~d}, J=3.6 \mathrm{~Hz}, 1 \mathrm{H}), 6.66(\mathrm{~d}, J=3.6 \mathrm{~Hz}, 1 \mathrm{H}), 5.52(\mathrm{~s}, 2 \mathrm{H}) ;{ }^{13} \mathrm{C}-\mathrm{NMR}$ $\left(100 \mathrm{MHz}, \mathrm{CDCl}_{3}\right) \delta 152.7,151.4,151.3,140.4,130.7\left(\mathrm{q}, \mathrm{J}_{\mathrm{CF}}=32.3 \mathrm{~Hz}\right), 129.0,127.9,126.1$ $\left(q, J_{C F}=3.6 \mathrm{~Hz}\right), 124.0\left(q, J_{C F}=272.6 \mathrm{~Hz}\right), 117.7,100.6,48.1$. HRMS $\left(\mathrm{ESI}^{+}\right) \mathrm{m} / z$ calcd. for $\mathrm{C}_{14} \mathrm{H}_{10} \mathrm{ClF}_{3} \mathrm{~N}_{3}[\mathrm{M}+\mathrm{H}]^{+}$312.0510, found 312.0509.

4-Chloro-7-(4-(methylsulfonyl)benzyl)-7H-pyrrolo[2,3-d]pyrimidine (34f). Compound $\mathbf{3 4 f}$ was prepared from $33(154 \mathrm{mg}, 1.00 \mathrm{mmol}$ ) and 4-methylsulfonylbenzyl bromide (299 mg, $1.20 \mathrm{mmol}$ ) in a fashion similar to the one described for compound 34a. Pale solid, $305 \mathrm{mg}$, yield 95\%. ${ }^{1} \mathrm{H}-\mathrm{NMR}\left(400 \mathrm{MHz}, \mathrm{CDCl}_{3}\right) \delta 8.67(\mathrm{~s}, 1 \mathrm{H}), 7.89(\mathrm{~d}, J=8.4 \mathrm{~Hz}, 2 \mathrm{H}), 7.38(\mathrm{~d}$, $J=8.4 \mathrm{~Hz}, 2 \mathrm{H}), 7.24(\mathrm{~d}, J=3.6 \mathrm{~Hz}, 1 \mathrm{H}), 6.69(\mathrm{~d}, J=3.6 \mathrm{~Hz}, 1 \mathrm{H}), 5.56(\mathrm{~s}, 2 \mathrm{H}), 3.02(\mathrm{~s}, 3 \mathrm{H})$; ${ }^{13} \mathrm{C}-\mathrm{NMR}\left(100 \mathrm{MHz}, \mathrm{CDCl}_{3}\right) \delta$ 152.7, $151.3(\times 2), 142.6,140.6,129.0,128.4,128.3,117.7,100.8$, 48.1, 44.6. HRMS $\left(\mathrm{ESI}^{+}\right) \mathrm{m} / z$ calcd. for $\mathrm{C}_{14} \mathrm{H}_{13} \mathrm{ClN}_{3} \mathrm{O}_{2} \mathrm{~S}[\mathrm{M}+\mathrm{H}]^{+} 322.0412$, found 322.0411 . 
4-((4-Chloro-7H-pyrrolo[2,3-d]pyrimidin-7-yl)methyl)benzonitrile (34g). Compound 34g was prepared from $33(154 \mathrm{mg}, 1.00 \mathrm{mmol})$ and 4-cyanobenzyl bromide $(236 \mathrm{mg}, 1.20 \mathrm{mmol})$ in a fashion similar to the one described for compound 34a [25]. White solid, $270 \mathrm{mg}$, quantitative yield. ${ }^{1} \mathrm{H}-\mathrm{NMR}\left(400 \mathrm{MHz}, \mathrm{CDCl}_{3}\right) \delta 8.66(\mathrm{~s}, 1 \mathrm{H}), 7.62(\mathrm{~d}, J=8.4 \mathrm{~Hz}, 2 \mathrm{H}), 7.29$ $(\mathrm{d}, J=8.4 \mathrm{~Hz}, 2 \mathrm{H}), 7.22(\mathrm{~d}, J=3.6 \mathrm{~Hz}, 1 \mathrm{H}), 6.68(\mathrm{~d}, J=3.6 \mathrm{~Hz}, 1 \mathrm{H}), 5.52(\mathrm{~s}, 2 \mathrm{H}) ;{ }^{13} \mathrm{C}-\mathrm{NMR}$ $\left(100 \mathrm{MHz}, \mathrm{CDCl}_{3}\right) \delta 152.8,151.4(\times 2), 141.7,132.9,128.9,128.1,118.4,117.7,112.4,100.9$, 48.2. HRMS $\left(\mathrm{ESI}^{+}\right) \mathrm{m} / z$ calcd. for $\mathrm{C}_{14} \mathrm{H}_{10} \mathrm{ClN}_{4}[\mathrm{M}+\mathrm{H}]^{+} 269.0589$, found 269.0589.

4-Chloro-7-(3-(trifluoromethyl)benzyl)-7H-pyrrolo[2,3-d]pyrimidine (34h). Compound 34h was prepared from $33(154 \mathrm{mg}, 1.00 \mathrm{mmol})$ and 3-trifluoromethylbenzyl bromide (286 mg, $1.20 \mathrm{mmol})$ in a fashion similar to the one described for compound 34a [24]. Yellowish solid, $296 \mathrm{mg}$, yield 95\%. ${ }^{1} \mathrm{H}-\mathrm{NMR}\left(400 \mathrm{MHz}, \mathrm{CDCl}_{3}\right) \delta 8.66(\mathrm{~s}, 1 \mathrm{H}), 7.55(\mathrm{~d}, J=8.0 \mathrm{~Hz}, 1 \mathrm{H})$, $7.51(\mathrm{~s}, 1 \mathrm{H}), 7.44(\mathrm{t}, J=8.0 \mathrm{~Hz}, 1 \mathrm{H}), 7.37(\mathrm{~d}, J=8.0 \mathrm{~Hz}, 1 \mathrm{H}), 7.22(\mathrm{~d}, J=3.6 \mathrm{~Hz}, 1 \mathrm{H}), 6.64(\mathrm{~d}$, $J=3.6 \mathrm{~Hz}, 1 \mathrm{H}), 5.51(\mathrm{~s}, 2 \mathrm{H}) ;{ }^{13} \mathrm{C}-\mathrm{NMR}\left(100 \mathrm{MHz}, \mathrm{CDCl}_{3}\right) \delta 152.6,151.3,151.2,137.5,131.5$ $\left(q, J_{C F}=33.9 \mathrm{~Hz}\right), 131.0,129.7,128.9,125.3\left(q, J_{C F}=3.4 \mathrm{~Hz}\right), 124.4\left(q, J_{C F}=3.4 \mathrm{~Hz}\right), 123.9$ $\left(\mathrm{q}, \mathrm{J}_{\mathrm{CF}}=273.5 \mathrm{~Hz}\right), 117.7,100.6,48.1$. HRMS $\left(\mathrm{ESI}^{+}\right) \mathrm{m} / z$ calcd. for $\mathrm{C}_{14} \mathrm{H}_{10} \mathrm{ClF}_{3} \mathrm{~N}_{3}[\mathrm{M}+\mathrm{H}]^{+}$ 312.0510, found 312.0510.

4-Chloro-7-(3-(methylsulfonyl)benzyl)-7H-pyrrolo[2,3-d]pyrimidine (34i). Compound 34i was prepared from $33(154 \mathrm{mg}, 1.00 \mathrm{mmol})$ and 3-methylsulfonylbenzyl bromide (300 mg, $1.20 \mathrm{mmol}$ ) in a fashion similar to the one described for compound 34a. Pale solid, $288 \mathrm{mg}$, yield $90 \% .{ }^{1} \mathrm{H}-\mathrm{NMR}\left(400 \mathrm{MHz}, \mathrm{CDCl}_{3}\right) \delta 8.66(\mathrm{~s}, 1 \mathrm{H}), 7.87(\mathrm{~d}, J=7.8 \mathrm{~Hz}, 1 \mathrm{H}), 7.86(\mathrm{~s}, 1 \mathrm{H})$, $7.53(\mathrm{t}, J=7.8 \mathrm{~Hz}, 1 \mathrm{H}), 7.46(\mathrm{~d}, J=7.8 \mathrm{~Hz}, 1 \mathrm{H}), 7.25(\mathrm{~d}, J=3.6 \mathrm{~Hz}, 1 \mathrm{H}), 6.66(\mathrm{~d}, J=3.6 \mathrm{~Hz}$, $1 \mathrm{H}), 5.54(\mathrm{~s}, 2 \mathrm{H}), 3.02(\mathrm{~s}, 3 \mathrm{H}) ;{ }^{13} \mathrm{C}-\mathrm{NMR}\left(100 \mathrm{MHz}, \mathrm{CDCl}_{3}\right) \delta 152.7,151.3,151.2,141.5$, $138.3,132.9,130.3,128.9,127.3,126.4,117.7,100.8,48.0,44.5$. HRMS $\left(\mathrm{ESI}^{+}\right) \mathrm{m} / \mathrm{z}$ calcd. for $\mathrm{C}_{14} \mathrm{H}_{13} \mathrm{ClN}_{3} \mathrm{O}_{2} \mathrm{~S}[\mathrm{M}+\mathrm{H}]^{+} 322.0412$, found 322.0408 .

3-((4-Chloro-7H-pyrrolo[2,3-d]pyrimidin-7-yl)methyl)benzonitrile (34j). Compound 34j was prepared from 33 (154 mg, $1.00 \mathrm{mmol})$ and 3-cyanobenzyl bromide $(235 \mathrm{mg}, 1.20 \mathrm{mmol})$ in a fashion similar to the one described for compound 34a. Pale solid, $273 \mathrm{mg}$, quantitative yield. ${ }^{1} \mathrm{H}-\mathrm{NMR}\left(400 \mathrm{MHz}, \mathrm{CDCl}_{3}\right) \delta 8.66(\mathrm{~s}, 1 \mathrm{H}), 7.59(\mathrm{td}, J=5.0,1.6 \mathrm{~Hz}, 1 \mathrm{H}), 7.49(\mathrm{~s}$, $1 \mathrm{H}), 7.46-7.44(\mathrm{~m}, 2 \mathrm{H}), 7.22(\mathrm{~d}, J=3.6 \mathrm{~Hz}, 1 \mathrm{H}), 6.68(\mathrm{~d}, J=3.6 \mathrm{~Hz}, 1 \mathrm{H}), 5.49(\mathrm{~s}, 2 \mathrm{H}) ;{ }^{13} \mathrm{C}-$ $\operatorname{NMR}\left(100 \mathrm{MHz}, \mathrm{CDCl}_{3}\right) \delta 152.7,151.3(\times 2), 138.1,132.0,131.9,131.0,130.0,128.8,118.3$, 117.7, 113.4, 100.9, 47.9. HRMS $\left(\mathrm{ESI}^{+}\right) \mathrm{m} / z$ calcd. for $\mathrm{C}_{14} \mathrm{H}_{10} \mathrm{ClN}_{4}[\mathrm{M}+\mathrm{H}]^{+} 269.0589$, found 269.0560 .

4-Chloro-7-(naphthalen-1-ylmethyl)-7H-pyrrolo[2,3-d]pyrimidine (34k). Compound $34 \mathbf{k}$ was prepared from 33 (154 mg, $1.00 \mathrm{mmol})$ and 1-(bromomethyl)naphthalene (265 mg, $1.20 \mathrm{mmol}$ ) in a fashion similar to the one described for compound 34a. Yellowish solid, $298 \mathrm{mg}$, quantitative yield. ${ }^{1} \mathrm{H}-\mathrm{NMR}\left(400 \mathrm{MHz}, \mathrm{CDCl}_{3}\right) \delta 8.74(\mathrm{~s}, 1 \mathrm{H}), 7.98(\mathrm{~d}, J=8.2 \mathrm{~Hz}, 1 \mathrm{H})$, 7.89-7.85 (m, 2H), 7.52-7.41 (m, 3H), $7.27(\mathrm{~d}, J=8.2 \mathrm{~Hz}, 1 \mathrm{H}), 7.09(\mathrm{~d}, J=3.6 \mathrm{~Hz}, 1 \mathrm{H}), 6.56(\mathrm{~d}$, $J=3.6 \mathrm{~Hz}, 1 \mathrm{H}), 5.90(\mathrm{~s}, 2 \mathrm{H}) ;{ }^{13} \mathrm{C}-\mathrm{NMR}\left(100 \mathrm{MHz}, \mathrm{CDCl}_{3}\right) \delta 152.4,151.2,151.0,134.0,131.5$, 131.3, 129.5, 129.1, 129.0, 127.2, 127.0, 126.4, 125.5, 123.0, 117.7, 100.1, 46.7. HRMS (ESI ${ }^{+}$) $\mathrm{m} / z$ calcd. for $\mathrm{C}_{17} \mathrm{H}_{13} \mathrm{ClN}_{3}[\mathrm{M}+\mathrm{H}]^{+}$294.0793, found 294.0791.

4-Chloro-7-(naphthalen-2-ylmethyl)-7H-pyrrolo[2,3-d]pyrimidine (341). Compound 341 was prepared from 33 (154 mg, $1.00 \mathrm{mmol})$ and 2-(bromomethyl)naphthalene (265 mg, $1.20 \mathrm{mmol})$ in a fashion similar to the one described for compound 34a. Pale solid, $302 \mathrm{mg}$, quantitative yield. ${ }^{1} \mathrm{H}-\mathrm{NMR}\left(400 \mathrm{MHz}, \mathrm{CDCl}_{3}\right) \delta 8.70(\mathrm{~s}, 1 \mathrm{H}), 7.80-7.75(\mathrm{~m}, 3 \mathrm{H}), 7.66(\mathrm{~s}, 1 \mathrm{H}), 7.49-7.45$ $(\mathrm{m}, 2 \mathrm{H}), 7.30(\mathrm{dd}, J=8.2,1.6 \mathrm{~Hz}, 1 \mathrm{H}), 7.24(\mathrm{~d}, J=3.6 \mathrm{~Hz}, 1 \mathrm{H}), 6.63(\mathrm{~d}, J=3.6 \mathrm{~Hz}, 1 \mathrm{H}), 5.60(\mathrm{~s}$, 2H); ${ }^{13}$ C-NMR $\left(100 \mathrm{MHz}, \mathrm{CDCl}_{3}\right) \delta 152.0,151.3,150.7,133.6,133.3,133.1,129.5,129.1,127.9$, $127.8,126.8,126.7,126.5,125.4,117.6,100.3,48.8$. HRMS $\left(\mathrm{ESI}^{+}\right) \mathrm{m} / z$ calcd. for $\mathrm{C}_{17} \mathrm{H}_{13} \mathrm{ClN}_{3}$ $[\mathrm{M}+\mathrm{H}]^{+}$294.0793, found 294.0787.

4-((4-Chloro-7H-pyrrolo[2,3-d]pyrimidin-7-yl)methyl)quinolone (34m). Compound 34m was prepared from $33(154 \mathrm{mg}, 1.00 \mathrm{mmol}$ ) and 4-(bromomethyl)quinoline $(266 \mathrm{mg}, 1.20 \mathrm{mmol})$ in a fashion similar to the one described for compound 34a. Tan solid, $274 \mathrm{mg}$, yield $93 \%$. ${ }^{1} \mathrm{H}-\mathrm{NMR}\left(400 \mathrm{MHz}, \mathrm{CDCl}_{3}\right) \delta 8.82(\mathrm{~d}, J=4.4 \mathrm{~Hz}, 1 \mathrm{H}), 8.70(\mathrm{~s}, 1 \mathrm{H}), 8.17(\mathrm{~d}, J=8.2 \mathrm{~Hz}, 1 \mathrm{H})$, 
$8.05(\mathrm{~d}, J=8.2 \mathrm{~Hz}, 1 \mathrm{H}), 7.77(\mathrm{td}, J=8.0,1.6 \mathrm{~Hz}, 1 \mathrm{H}), 7.61(\mathrm{td}, J=8.0,1.6 \mathrm{~Hz}, 1 \mathrm{H}), 7.21(\mathrm{~d}$, $J=3.6 \mathrm{~Hz}, 1 \mathrm{H}), 6.85(\mathrm{~d}, J=4.4 \mathrm{~Hz}, 1 \mathrm{H}), 6.70(\mathrm{~d}, J=3.6 \mathrm{~Hz}, 1 \mathrm{H}), 5.96(\mathrm{~s}, 2 \mathrm{H}) ;{ }^{13} \mathrm{C}-\mathrm{NMR}$ $\left(100 \mathrm{MHz}_{2} \mathrm{CDCl}_{3}\right) \delta 152.8,151.4,151.3,150.4,148.5,141.5,130.7,130.0,129.1,127.7,126.0$, 122.6, 119.6, 117.7, 100.9, 45.3. HRMS $\left(\mathrm{ESI}^{+}\right) \mathrm{m} / \mathrm{z}$ calcd. for $\mathrm{C}_{16} \mathrm{H}_{12} \mathrm{ClN}_{4}[\mathrm{M}+\mathrm{H}]^{+} 295.0745$, found 295.0744 .

4-((4-Chloro-7H-pyrrolo[2,3-d]pyrimidin-7-yl)methyl)-1-naphthonitrile (34n). Compound 34n was prepared from 33 (154 mg, $1.00 \mathrm{mmol}$ ) and 4-(bromomethyl)-1-naphthonitrile (295 mg, $1.20 \mathrm{mmol}$ ) in a fashion similar to the one described for compound 34a. Pale solid, $296 \mathrm{mg}$, yield 93\%. ${ }^{1} \mathrm{H}-\mathrm{NMR}\left(400 \mathrm{MHz}, \mathrm{CDCl}_{3}\right) \delta 8.71(\mathrm{~s}, 1 \mathrm{H}), 8.31(\mathrm{~d}, J=8.4 \mathrm{~Hz}, 1 \mathrm{H}), 8.16(\mathrm{~d}$, $J=8.4 \mathrm{~Hz}, 1 \mathrm{H}), 7.84(\mathrm{~d}, J=7.4 \mathrm{~Hz}, 1 \mathrm{H}), 7.74(\mathrm{td}, J=7.4,1.2 \mathrm{~Hz}, 1 \mathrm{H}), 7.67(\mathrm{td}, J=7.4,1.2 \mathrm{~Hz}$, $1 \mathrm{H}), 7.17(\mathrm{~d}, J=3.6 \mathrm{~Hz}, 1 \mathrm{H}), 7.12(\mathrm{~d}, J=7.4 \mathrm{~Hz}, 1 \mathrm{H}), 6.66(\mathrm{~d}, J=3.6 \mathrm{~Hz}, 1 \mathrm{H}), 5.98(\mathrm{~s}, 2 \mathrm{H})$; ${ }^{13} \mathrm{C}-\mathrm{NMR}\left(100 \mathrm{MHz}, \mathrm{CDCl}_{3}\right) \delta 152.8,151.3(\times 2), 137.8,132.7,132.3,130.7,129.0,128.9,128.8$, $126.4,124.8,123.6,117.7,117.5,111.4,100.9,46.2$. HRMS $\left(\mathrm{ESI}^{+}\right) \mathrm{m} / z$ calcd. for $\mathrm{C}_{18} \mathrm{H}_{12} \mathrm{ClN}_{4}$ $[\mathrm{M}+\mathrm{H}]^{+}$319.0745, found 319.0731 .

2-Chloro-6-((4-chloro-7H-pyrrolo[2,3-d]pyrimidin-7-yl)methyl)quinolone (34o). Compound 34o was prepared from $33(154 \mathrm{mg}, 1.00 \mathrm{mmol})$ and 6-(bromomethyl)-2-chloroquinoline (307 $\mathrm{mg}$, $1.20 \mathrm{mmol}$ ) in a fashion similar to the one described for compound 34a. Pale solid, $329 \mathrm{mg}$, quantitative yield. ${ }^{1} \mathrm{H}-\mathrm{NMR}\left(400 \mathrm{MHz}, \mathrm{CDCl}_{3}\right) \delta 8.68(\mathrm{~s}, 1 \mathrm{H}), 8.03(\mathrm{~d}, J=8.7 \mathrm{~Hz}, 1 \mathrm{H}), 7.98$ $(\mathrm{d}, J=8.7 \mathrm{~Hz}, 1 \mathrm{H}), 7.61-7.58(\mathrm{~m}, 2 \mathrm{H}), 7.39(\mathrm{~d}, J=8.6 \mathrm{~Hz}, 1 \mathrm{H}), 7.27(\mathrm{~d}, J=3.6 \mathrm{~Hz}, 1 \mathrm{H}), 6.67(\mathrm{~d}$, $J=3.6 \mathrm{~Hz}, 1 \mathrm{H}), 5.64(\mathrm{~s}, 2 \mathrm{H}) ;{ }^{13} \mathrm{C}-\mathrm{NMR}\left(100 \mathrm{MHz}, \mathrm{CDCl}_{3}\right) \delta 152.7,151.4(\times 2), 151.3,147.6$, $138.8,135.4,130.0,129.7,129.1,126.9,126.1,123.2,117.7,100.6,48.4$. HRMS $\left(\mathrm{ESI}^{+}\right) \mathrm{m} / z$ calcd. for $\mathrm{C}_{16} \mathrm{H}_{11} \mathrm{Cl}_{2} \mathrm{~N}_{4}[\mathrm{M}+\mathrm{H}]^{+}$329.0355, found 329.0342 .

N-(3-Chlorobenzyl)-7-(4-nitrobenzyl)-7H-pyrrolo [2,3-d]pyrimidin-4-amine (1). A mixture of 34a $(289 \mathrm{mg}, 1.00 \mathrm{mmol})$, DIPEA $(0.35 \mathrm{~mL}, 2.01 \mathrm{mmol})$ and 3-chlorobenzylamine $(244 \mu \mathrm{L}$, $2.00 \mathrm{mmol})$ in anhydrous 2-methoxyethan-1-ol $(10 \mathrm{~mL})$ was heated at $100{ }^{\circ} \mathrm{C}$ for $20 \mathrm{~h}$. Additional 3-chlorobenzylamine $(244 \mu \mathrm{L}, 2.00 \mathrm{mmol})$ was added and the resulting mixture was heated at $100{ }^{\circ} \mathrm{C}$ for $10 \mathrm{~h}$. After being allowed to cool to $\mathrm{rt}$, the reaction mixture was concentrated and the residue was partitioned between EtOAc $(20 \mathrm{~mL})$ and water $(40 \mathrm{~mL})$. After separation, the aqueous layer was extracted with EtOAc $(20 \mathrm{~mL})$. The combined organic layer was concentrated and the residue was purified by flash column chromatography (30\%-90\% EtOAc/hexanes) to afford compound 1 as a brownish syrup (370 mg, 94\%). ${ }^{1} \mathrm{H}-\mathrm{NMR}\left(400 \mathrm{MHz}, \mathrm{CDCl}_{3}\right) \delta 8.39(\mathrm{~s}, 1 \mathrm{H}), 8.15(\mathrm{~d}, J=8.6 \mathrm{~Hz}, 2 \mathrm{H}), 7.38$ (s, $1 \mathrm{H}), 7.30(\mathrm{~d}, J=8.6 \mathrm{~Hz}, 2 \mathrm{H}), 7.27-7.25(\mathrm{~m}, 3 \mathrm{H}), 6.92(\mathrm{~d}, J=3.6 \mathrm{~Hz}, 1 \mathrm{H}), 6.40(\mathrm{~d}, J=3.6 \mathrm{~Hz}$, $1 \mathrm{H}), 5.49(\mathrm{~s}, 2 \mathrm{H}), 5.43(\mathrm{t}, J=6.0 \mathrm{~Hz}, 1 \mathrm{H}), 4.84(\mathrm{~d}, J=6.0 \mathrm{~Hz}, 2 \mathrm{H}) ;{ }^{13} \mathrm{C}-\mathrm{NMR}(100 \mathrm{MHz}$, $\left.\mathrm{CDCl}_{3}\right) \delta 156.4,152.6,150.4,147.7,144.8,141.1,134.8,130.1,128.1,127.8(\times 2), 125.9,124.2$, $124.1,103.1,98.7,47.5,44.6$. HRMS $\left(\mathrm{ESI}^{+}\right) \mathrm{m} / z$ calcd. for $\mathrm{C}_{20} \mathrm{H}_{17} \mathrm{ClN}_{5} \mathrm{O}_{2}[\mathrm{M}+\mathrm{H}]^{+} 394.1065$, found 394.1065 .

7-(4-Aminobenzyl)-N-(3-chlorobenzyl)-7H-pyrrolo[2,3-d]pyrimidin-4-amine (2). A mixture of compound 1 (173 mg, $0.439 \mathrm{mmol})$ and $\mathrm{SnCl}_{2}(583 \mathrm{mg}, 3.07 \mathrm{mmol})$ in anhydrous $\mathrm{EtOH}$ $(6 \mathrm{~mL})$ was heated at $70^{\circ} \mathrm{C}$ for $21 \mathrm{~h}$. After being allowed to cool to rt, the reaction mixture was diluted with EtOAc $(15 \mathrm{~mL})$ and saturated $\mathrm{NaHCO}_{3}(8 \mathrm{~mL})$ and water $(2 \mathrm{~mL})$ were added. The resulting mixture was filtered through a pad of Celite. The organic layer of the filtrate was separated, washed with brine $(20 \mathrm{~mL})$ and dried over $\mathrm{Na}_{2} \mathrm{SO}_{4}$. After filtration, the filtrate was concentrated and the residue was purified by flash column chromatography using $\left(0 \%-10 \% \mathrm{MeOH} / \mathrm{CH}_{2} \mathrm{Cl}_{2}\right)$ to afford compound 2 as a pale solid $(94 \mathrm{mg}, 59 \%) .{ }^{1} \mathrm{H}-$ $\operatorname{NMR}\left(400 \mathrm{MHz}, \mathrm{CDCl}_{3}\right) \delta 8.42(\mathrm{~s}, 1 \mathrm{H}), 7.37(\mathrm{~s}, 1 \mathrm{H}), 7.26-7.24(\mathrm{~m}, 3 \mathrm{H}), 7.05(\mathrm{~d}, J=8.6 \mathrm{~Hz}, 2 \mathrm{H})$, $6.87(\mathrm{~d}, J=3.6 \mathrm{~Hz}, 1 \mathrm{H}), 6.61(\mathrm{~d}, J=8.6 \mathrm{~Hz}, 2 \mathrm{H}), 6.29(\mathrm{~d}, J=3.6 \mathrm{~Hz}, 1 \mathrm{H}), 5.32(\mathrm{t}, J=6.0 \mathrm{~Hz}$, $1 \mathrm{H}), 5.25(\mathrm{~s}, 2 \mathrm{H}), 4.83(\mathrm{~d}, J=6.0 \mathrm{~Hz}, 2 \mathrm{H}), 3.66(\mathrm{~s}, 2 \mathrm{H}) ;{ }^{13} \mathrm{C}-\mathrm{NMR}\left(100 \mathrm{MHz}, \mathrm{CDCl}_{3}\right) \delta 156.3$, 152.1, 150.2, 146.2, 141.3, 134.7, 130.1, 129.2, 127.8, 127.7, 127.2, 125.9, 124.3, 115.4, 103.1, 97.6, 47.8, 44.6. HRMS $\left(\mathrm{ESI}^{+}\right) \mathrm{m} / z$ calcd. for $\mathrm{C}_{20} \mathrm{H}_{19} \mathrm{ClN}_{5}[\mathrm{M}+\mathrm{H}]^{+} 364.1323$, found 364.1322.

7-Benzyl-N-(3-chlorobenzyl)-7H-pyrrolo[2,3-d]pyrimidin-4-amine (3). A mixture of $\mathbf{3 4 b}$ (74 mg, $0.30 \mathrm{mmol})$, DIPEA (0.21 mL, $1.2 \mathrm{mmol})$ and 3-chlorobenzylamine $(0.15 \mathrm{~mL}, 1.2 \mathrm{mmol})$ in 
anhydrous 2-methoxyethan-1-ol (3 mL) was heated at $100{ }^{\circ} \mathrm{C}$ for $24 \mathrm{~h}$. After being allowed to cool to rt, the reaction mixture was concentrated and the residue was partitioned between EtOAc $(10 \mathrm{~mL})$ and water $(10 \mathrm{~mL})$. After separation, the organic layer was concentrated and the residue was purified by flash column chromatography (10\%-80\% EtOAc/hexanes) to afford compound 3 as a yellowish solid $(79 \mathrm{mg}, 74 \%)$. ${ }^{1} \mathrm{H}-\mathrm{NMR}\left(400 \mathrm{MHz}, \mathrm{CDCl}_{3}\right) \delta$ $8.42(\mathrm{~s}, 1 \mathrm{H}), 7.38(\mathrm{~s}, 1 \mathrm{H}), 7.33-7.25(\mathrm{~m}, 8 \mathrm{H}), 7.22-7.18(\mathrm{~m}, 2 \mathrm{H}), 6.89(\mathrm{~d}, J=3.6 \mathrm{~Hz}, 1 \mathrm{H}), 6.33$ $(\mathrm{d}, J=3.6 \mathrm{~Hz}, 1 \mathrm{H}), 5.39$ (s, 2H), $5.36(\mathrm{~s}, 1 \mathrm{H}), 4.83(\mathrm{~d}, J=6.0 \mathrm{~Hz}, 2 \mathrm{H})$; ${ }^{13} \mathrm{C}-\mathrm{NMR}(100 \mathrm{MHz}$, $\left.\mathrm{CDCl}_{3}\right) \delta 156.3,152.2,150.4,141.3,137.4,134.7,130.1,128.9,127.9,127.8,127.7,127.6,125.9$, $124.5,103.0,97.9,48.1,44.7$. HRMS $\left(\mathrm{ESI}^{+}\right) \mathrm{m} / z$ calcd. for $\mathrm{C}_{20} \mathrm{H}_{18} \mathrm{ClN}_{4}[\mathrm{M}+\mathrm{H}]^{+} 349.1215$, found 349.1214 .

N-(3-Chlorobenzyl)-7-(2-nitrobenzyl)-7H-pyrrolo[2,3-d]pyrimidin-4-amine (4). Compound 4 was prepared from $34 \mathrm{c}(80 \mathrm{mg}, 0.28 \mathrm{mmol})$ and 3-chlorobenzylamine $(135 \mu \mathrm{L}, 1.10 \mathrm{mmol})$ in a fashion similar to the one described for compound 3. Yellow solid, $95 \mathrm{mg}$, yield 87\%. ${ }^{1} \mathrm{H}-\mathrm{NMR}\left(400 \mathrm{MHz}, \mathrm{CDCl}_{3}\right) \delta 8.37(\mathrm{~s}, 1 \mathrm{H}), 8.13(\mathrm{dd}, J=8.1,1.6 \mathrm{~Hz}, 1 \mathrm{H}), 7.49-7.39$ $(\mathrm{m}, 3 \mathrm{H}), 7.30-7.26(\mathrm{~m}, 3 \mathrm{H}), 6.99(\mathrm{~d}, J=3.6 \mathrm{~Hz}, 1 \mathrm{H}), 6.76(\mathrm{dd}, J=8.1,1.6 \mathrm{~Hz}, 1 \mathrm{H}), 6.43(\mathrm{~d}$, $J=3.6 \mathrm{~Hz}, 1 \mathrm{H}), 5.82(\mathrm{~s}, 2 \mathrm{H}), 5.41(\mathrm{t}, J=6.0 \mathrm{~Hz}, 1 \mathrm{H}), 4.84(\mathrm{~d}, J=6.0 \mathrm{~Hz}, 2 \mathrm{H}) ;{ }^{13} \mathrm{C}-\mathrm{NMR}(100$ $\left.\mathrm{MHz}_{,} \mathrm{CDCl}_{3}\right) \delta 156.4,152.6,150.6,147.5,141.2,134.7,134.2,133.7,130.2,129.9,128.6,127.9$, $127.8,125.9,125.4,124.9,103.2,98.6,45.7,44.7$. HRMS $\left(\mathrm{ESI}^{+}\right) \mathrm{m} / z$ calcd. for $\mathrm{C}_{20} \mathrm{H}_{17} \mathrm{ClN}_{5} \mathrm{O}_{2}$ $[\mathrm{M}+\mathrm{H}]^{+} 394.1065$, found 394.1068.

N-(3-Chlorobenzyl)-7-(3-nitrobenzyl)-7H-pyrrolo[2,3-d]pyrimidin-4-amine (5). Compound 5 was prepared from $34 \mathbf{d}(80 \mathrm{mg}, 0.28 \mathrm{mmol})$ and 3-chlorobenzylamine $(135 \mu \mathrm{L}, 1.10 \mathrm{mmol})$ in a fashion similar to the one described for compound 3. Yellow solid, $103 \mathrm{mg}$, yield $94 \%$. ${ }^{1} \mathrm{H}-\mathrm{NMR}\left(400 \mathrm{MHz}, \mathrm{CDCl}_{3}\right) \delta 8.40(\mathrm{~s}, 1 \mathrm{H}), 8.12(\mathrm{ddd}, J=7.8,3.8,1.8 \mathrm{~Hz}, 1 \mathrm{H}), 8.05(\mathrm{~s}, 1 \mathrm{H})$, 7.53-7.46 (m, 2H), $7.38(\mathrm{~s}, 1 \mathrm{H}), 7.28-7.25(\mathrm{~m}, 3 \mathrm{H}), 6.94(\mathrm{~d}, J=3.6 \mathrm{~Hz}, 1 \mathrm{H}), 6.41(\mathrm{~d}, J=3.6 \mathrm{~Hz}$, $1 \mathrm{H}), 5.49(\mathrm{~s}, 2 \mathrm{H}), 5.46(\mathrm{t}, J=6.0 \mathrm{~Hz}, 1 \mathrm{H}), 4.84(\mathrm{~d}, J=6.0 \mathrm{~Hz}, 2 \mathrm{H}) ;{ }^{13} \mathrm{C}-\mathrm{NMR}(100 \mathrm{MHz}$, $\left.\mathrm{CDCl}_{3}\right) \delta 156.4,152.6,150.3,148.6,141.1,139.7,134.7,133.5,130.1,129.9,127.8,127.7,125.9$, $124.0,123.0,122.3,103.1,98.7,47.4,44.6$. HRMS $\left(\mathrm{ESI}^{+}\right) \mathrm{m} / z$ calcd. for $\mathrm{C}_{20} \mathrm{H}_{17} \mathrm{ClN}_{5} \mathrm{O}_{2}$ $[\mathrm{M}+\mathrm{H}]^{+}$394.1065, found 394.1065.

N-(3-Chlorobenzyl)-7-(4-(trifluoromethyl)benzyl)-7H-pyrrolo[2,3-d]pyrimidin-4-amine (6). Compound 6 was prepared from $34 \mathrm{e}(62 \mathrm{mg}, 0.20 \mathrm{mmol})$ and 3-chlorobenzylamine $(98 \mu \mathrm{L}$, $0.80 \mathrm{mmol}$ ) in a fashion similar to the one described for compound 3. Yellow syrup, $74 \mathrm{mg}$, yield 89\%. ${ }^{1} \mathrm{H}-\mathrm{NMR}\left(400 \mathrm{MHz} \mathrm{CDCl}_{3}\right) \delta 8.41(\mathrm{~s}, 1 \mathrm{H}), 7.56(\mathrm{~d}, \mathrm{~J}=8.2 \mathrm{~Hz}, 2 \mathrm{H}), 7.39(\mathrm{~s}$, $1 \mathrm{H}), 7.30-7.27(\mathrm{~m}, 5 \mathrm{H}), 6.91(\mathrm{~d}, J=3.6 \mathrm{~Hz}, 1 \mathrm{H}), 6.37(\mathrm{~d}, J=3.6 \mathrm{~Hz}, 1 \mathrm{H}), 5.45(\mathrm{~s}, 2 \mathrm{H}), 5.33(\mathrm{t}$, $J=6.0 \mathrm{~Hz}, 1 \mathrm{H}), 4.85(\mathrm{~d}, J=6.0 \mathrm{~Hz}, 2 \mathrm{H}) ;{ }^{13} \mathrm{C}-\mathrm{NMR}\left(100 \mathrm{MHz}, \mathrm{CDCl}_{3}\right) \delta 156.4,152.5,150.4$, $141.5,141.2,134.7,130.2\left(q, J_{C F}=32.5 \mathrm{~Hz}\right), 130.1,127.9,127.8,127.7,125.9$ (q, J $\mathrm{JF}_{\mathrm{CF}}=3.6 \mathrm{~Hz}$ ), $125.9,124.2,124.1\left(\mathrm{q}, \mathrm{J}_{\mathrm{CF}}=273.8 \mathrm{~Hz}\right), 103.1,98.3,47.7,44.7$. HRMS $\left(\mathrm{ESI}^{+}\right) \mathrm{m} / \mathrm{z}$ calcd. for $\mathrm{C}_{21} \mathrm{H}_{17} \mathrm{ClF}_{3} \mathrm{~N}_{5}[\mathrm{M}+\mathrm{H}]^{+}$431.1119, found 431.1112 .

N-(3-Chlorobenzyl)-7-(4-(methylsulfonyl)benzyl)-7H-pyrrolo[2,3-d]pyrimidin-4-amine (7). Compound 7 was prepared from $34 \mathrm{f}(64 \mathrm{mg}, 0.20 \mathrm{mmol})$ and 3-chlorobenzylamine $(98 \mu \mathrm{L}$, $0.80 \mathrm{mmol}$ ) in a fashion similar to the one described for compound 3. Pale solid, $82 \mathrm{mg}$, yield 96\%. ${ }^{1} \mathrm{H}-\mathrm{NMR}\left(400 \mathrm{MHz}, \mathrm{CDCl}_{3}\right) \delta 8.40(\mathrm{~s}, 1 \mathrm{H}), 7.87(\mathrm{~d}, J=8.4 \mathrm{~Hz}, 2 \mathrm{H}), 7.38(\mathrm{~s}, 1 \mathrm{H})$, $7.34(\mathrm{~d}, J=8.4 \mathrm{~Hz}, 2 \mathrm{H}), 7.29-7.26(\mathrm{~m}, 3 \mathrm{H}), 6.92(\mathrm{~d}, J=3.6 \mathrm{~Hz}, 1 \mathrm{H}), 6.40(\mathrm{~d}, J=3.6 \mathrm{~Hz}, 1 \mathrm{H})$, $5.49(\mathrm{~s}, 2 \mathrm{H}), 5.39(\mathrm{t}, J=6.0 \mathrm{~Hz}, 1 \mathrm{H}), 4.84(\mathrm{~d}, J=6.0 \mathrm{~Hz}, 2 \mathrm{H}), 3.01(\mathrm{~s}, 3 \mathrm{H}) ;{ }^{13} \mathrm{C}-\mathrm{NMR}(100 \mathrm{MHz}$, $\left.\mathrm{CDCl}_{3}\right) \delta 156.4,152.6,150.4,143.8,141.2,140.1,134.7,130.1,128.2,128.1,127.8(\times 2), 125.9$, $124.2,103.1,98.6,47.6,44.6(\times 2)$. HRMS $\left(\mathrm{ESI}^{+}\right) \mathrm{m} / \mathrm{z}$ calcd. for $\mathrm{C}_{21} \mathrm{H}_{20} \mathrm{ClN}_{4} \mathrm{O}_{2} \mathrm{~S}[\mathrm{M}+\mathrm{H}]^{+}$ 427.0990, found 427.0993.

4-((4-((3-Chlorobenzyl)amino)-7H-pyrrolo[2,3-d]pyrimidin-7-yl)methyl)benzonitrile (8). Compound 8 was prepared from $34 \mathrm{~g}(54 \mathrm{mg}, 0.20 \mathrm{mmol})$ and 3-chlorobenzylamine $(98 \mu \mathrm{L}$, $0.80 \mathrm{mmol})$ in a fashion similar to the one described for compound 3. Yellow syrup, 70 mg, yield 93\%. ${ }^{1} \mathrm{H}-\mathrm{NMR}\left(400 \mathrm{MHz}, \mathrm{CDCl}_{3}\right) \delta 8.41(\mathrm{~s}, 1 \mathrm{H}), 7.60(\mathrm{~d}, J=8.6 \mathrm{~Hz}, 2 \mathrm{H}), 7.40(\mathrm{~s}$, 1H), 7.31-7.27 (m, 5H), $6.92(\mathrm{~d}, J=3.6 \mathrm{~Hz}, 1 \mathrm{H}), 6.41(\mathrm{~d}, J=3.6 \mathrm{~Hz}, 1 \mathrm{H}), 5.47(\mathrm{~s}, 2 \mathrm{H}), 5.43(\mathrm{t}$, $J=6.0 \mathrm{~Hz}, 1 \mathrm{H}), 4.86(\mathrm{~d}, J=6.0 \mathrm{~Hz}, 2 \mathrm{H}) ;{ }^{13} \mathrm{C}-\mathrm{NMR}\left(100 \mathrm{MHz}, \mathrm{CDCl}_{3}\right) \delta 156.4,152.5,150.4$, 
142.9, 141.1, 134.7, 132.7, 130.1, 127.9, 127.8 (×2), 125.9, 124.1, 118.7, 111.8, 103.1, 98.6, 47.7, 44.6. HRMS $\left(\mathrm{ESI}^{+}\right) \mathrm{m} / z$ calcd. for $\mathrm{C}_{21} \mathrm{H}_{17} \mathrm{ClN}_{5}[\mathrm{M}+\mathrm{H}]^{+} 374.1167$, found 374.1174 .

N-(3-Chlorobenzyl)-7-(3-(trifluoromethyl)benzyl)-7H-pyrrolo[2,3-d]pyrimidin-4-amine (9). Compound 9 was prepared from $34 \mathrm{~h}(79 \mathrm{mg}, 0.25 \mathrm{mmol})$ and 3-chlorobenzylamine $(122 \mu \mathrm{L}$, $1.00 \mathrm{mmol}$ ) in a fashion similar to the one described for compound 3. Pale solid, $99 \mathrm{mg}$, yield 94\%. ${ }^{1} \mathrm{H}-\mathrm{NMR}\left(400 \mathrm{MHz}, \mathrm{CDCl}_{3}\right) \delta 8.42(\mathrm{~s}, 1 \mathrm{H}), 7.53(\mathrm{~d}, J=8.0 \mathrm{~Hz}, 2 \mathrm{H}), 7.48(\mathrm{~s}, 1 \mathrm{H})$, $7.44-7.33(\mathrm{~m}, 3 \mathrm{H}), 7.29-7.25(\mathrm{~m}, 3 \mathrm{H}), 6.91(\mathrm{~d}, J=3.6 \mathrm{~Hz}, 1 \mathrm{H}), 6.37(\mathrm{~d}, J=3.6 \mathrm{~Hz}, 1 \mathrm{H}), 5.45(\mathrm{~s}$, $2 \mathrm{H}), 5.37(\mathrm{t}, J=6.0 \mathrm{~Hz}, 1 \mathrm{H}), 4.84(\mathrm{~d}, J=6.0 \mathrm{~Hz}, 2 \mathrm{H}) ;{ }^{13} \mathrm{C}-\mathrm{NMR}\left(100 \mathrm{MHz}, \mathrm{CDCl}_{3}\right) \delta 156.4$, $152.5,150.4,141.2,138.5,134.7,131.3\left(q, J_{C F}=32.2 \mathrm{~Hz}\right), 130.9,130.1,129.5,127.9,127.8,125.9$, $124.8\left(\mathrm{q}, \mathrm{J}_{\mathrm{CF}}=3.8 \mathrm{~Hz}\right), 124.3\left(\mathrm{q}, \mathrm{J}_{\mathrm{CF}}=3.8 \mathrm{~Hz}\right), 124.2124 .0\left(\mathrm{q}, \mathrm{J}_{\mathrm{CF}}=273.1 \mathrm{~Hz}\right), 103.1,98.4$, 47.6, 44.7. HRMS $\left(\mathrm{ESI}^{+}\right) \mathrm{m} / z$ calcd. for $\mathrm{C}_{21} \mathrm{H}_{17} \mathrm{ClF}_{3} \mathrm{~N}_{5}[\mathrm{M}+\mathrm{H}]^{+} 431.1119$, found 431.1109.

N-(3-Chlorobenzyl)-7-(3-(methylsulfonyl)benzyl)-7H-pyrrolo[2,3-d]pyrimidin-4-amine (10). Compound 10 was prepared from $34 \mathbf{i}(80 \mathrm{mg}, 0.25 \mathrm{mmol})$ and 3-chlorobenzylamine $(122 \mu \mathrm{L}$, $1.00 \mathrm{mmol}$ ) in a fashion similar to the one described for compound 3. Pale solid, $105 \mathrm{mg}$, yield 99\%. ${ }^{1} \mathrm{H}-\mathrm{NMR}\left(400 \mathrm{MHz}, \mathrm{CDCl}_{3}\right) \delta 8.39(\mathrm{~s}, 1 \mathrm{H}), 7.84(\mathrm{dd}, J=8.0,1.6 \mathrm{~Hz}, 1 \mathrm{H}), 7.81$ $(\mathrm{s}, 1 \mathrm{H}), 7.50(\mathrm{t}, J=8.0 \mathrm{~Hz}, 1 \mathrm{H}), 7.43(\mathrm{dd}, J=8.0,1.6 \mathrm{~Hz}, 1 \mathrm{H}), 7.28-7.25(\mathrm{~m}, 3 \mathrm{H}), 6.92$ $(\mathrm{d}, J=3.6 \mathrm{~Hz}, 1 \mathrm{H}), 6.39(\mathrm{~d}, J=3.6 \mathrm{~Hz}, 1 \mathrm{H}), 5.47(\mathrm{~s}, 2 \mathrm{H}), 5.41(\mathrm{t}, J=6.0 \mathrm{~Hz}, 1 \mathrm{H}), 4.84(\mathrm{~d}$, $J=6.0 \mathrm{~Hz}, 2 \mathrm{H}), 3.01$ (s, 3H); ${ }^{13} \mathrm{C}-\mathrm{NMR}\left(100 \mathrm{MHz}, \mathrm{CDCl}_{3}\right) \delta 156.4,152.5,150.3,141.2,141.1$, 139.5, 134.7, 132.7, 130.2, 130.1, 127.9, 127.8, 126.9, 126.1, 125.9, 124.1, 103.1, 98.6, 47.5, 44.6 (×2). HRMS $\left(\mathrm{ESI}_{+}\right) \mathrm{m} / \mathrm{z}$ calcd. for $\mathrm{C}_{21} \mathrm{H}_{20} \mathrm{ClN}_{4} \mathrm{O}_{2} \mathrm{~S}[\mathrm{M}+\mathrm{H}]^{+} 427.0990$, found 427.0980.

3-((4-((3-Chlorobenzyl)amino)-7H-pyrrolo[2,3-d]pyrimidin-7-yl)methyl)benzonitrile (11). Compound 11 was prepared from $34 \mathbf{j}(67 \mathrm{mg}, 0.25 \mathrm{mmol})$ and 3-chlorobenzylamine $(122 \mu \mathrm{L}$, $1.00 \mathrm{mmol}$ ) in a fashion similar to the one described for compound 3. Pale solid, $93 \mathrm{mg}$, quantitative yield. ${ }^{1} \mathrm{H}-\mathrm{NMR}\left(400 \mathrm{MHz}, \mathrm{CDCl}_{3}\right) \delta 8.40(\mathrm{~s}, 1 \mathrm{H}), 7.55(\mathrm{dd}, J=8.2,1.8 \mathrm{~Hz}$, $1 \mathrm{H}), 7.44-7.38(\mathrm{~m}, 4 \mathrm{H}), 7.29-7.25(\mathrm{~m}, 3 \mathrm{H}), 6.90(\mathrm{~d}, J=3.6 \mathrm{~Hz}, 1 \mathrm{H}), 6.39(\mathrm{~d}, J=3.6 \mathrm{~Hz}, 1 \mathrm{H})$, $5.42(\mathrm{t}, J=6.0 \mathrm{~Hz}, 1 \mathrm{H}), 5.41(\mathrm{~s}, 2 \mathrm{H}), 4.84(\mathrm{~d}, J=6.0 \mathrm{~Hz}, 2 \mathrm{H}) ;{ }^{13} \mathrm{C}-\mathrm{NMR}\left(100 \mathrm{MHz}, \mathrm{CDCl}_{3}\right)$ $\delta 156.4,152.6,150.3,141.1,139.2,134.7,131.8,131.6,130.8,130.1,129.8,127.9,127.8,125.9$, $124.0,118.6,113.1,103.1,98.6,47.3,44.6$. HRMS $\left(\mathrm{ESI}^{+}\right) \mathrm{m} / z$ calcd. for $\mathrm{C}_{21} \mathrm{H}_{17} \mathrm{ClN}_{5}[\mathrm{M}+\mathrm{H}]^{+}$ 374.1167 , found 374.1166 .

N-(3-Chlorobenzyl)-7-(naphthalen-1-ylmethyl)-7H-pyrrolo[2,3-d]pyrimidin-4-amine (12). Compound 12 was prepared from $34 \mathbf{k}(89 \mathrm{mg}, 0.30 \mathrm{mmol})$ and 3-chlorobenzylamine $(0.15 \mathrm{~mL}$, $1.2 \mathrm{mmol}$ ) in a fashion similar to the one described for compound 3. Yellowish solid, $91 \mathrm{mg}$, yield 75\%. ${ }^{1} \mathrm{H}-\mathrm{NMR}\left(400 \mathrm{MHz}, \mathrm{CDCl}_{3}\right) \delta 8.45(\mathrm{~s}, 1 \mathrm{H}), 7.81-7.75(\mathrm{~m}, 3 \mathrm{H}), 7.65$ (s, $1 \mathrm{H}), 7.48-7.44(\mathrm{~m}, 2 \mathrm{H}), 7.39(\mathrm{~s}, 1 \mathrm{H}), 7.33(\mathrm{dd}, J=8.6,1.8 \mathrm{~Hz}, 1 \mathrm{H}), 7.28-7.24(\mathrm{~m}, 3 \mathrm{H}), 6.93$ $(\mathrm{d}, J=3.6 \mathrm{~Hz}, 1 \mathrm{H}), 6.34(\mathrm{~d}, J=3.6 \mathrm{~Hz}, 1 \mathrm{H}), 5.55(\mathrm{~s}, 2 \mathrm{H}), 5.39(\mathrm{t}, J=6.0 \mathrm{~Hz}, 1 \mathrm{H}), 4.84(\mathrm{~d}$, $J=6.0 \mathrm{~Hz}, 2 \mathrm{H}) ;{ }^{13} \mathrm{C}-\mathrm{NMR}\left(100 \mathrm{MHz}, \mathrm{CDCl}_{3}\right) \delta 156.3,152.3,150.4,141.3,134.9,134.7,133.4$, 133.0, 130.1, 128.3, 128.0, 127.8 (×2), 127.7, 126.5 (×2), 126.2, 125.9, 125.6, 124.5, 103.1, 98.0, 48.3, 44.7. HRMS $\left(\mathrm{ESI}^{+}\right) \mathrm{m} / z$ calcd. for $\mathrm{C}_{24} \mathrm{H}_{20} \mathrm{ClN}_{4}[\mathrm{M}+\mathrm{H}]^{+} 399.1371$, found 399.1367.

N-(3-Chlorobenzyl)-7-(naphthalen-2-ylmethyl)-7H-pyrrolo[2,3-d]pyrimidin-4-amine (13). Compound 13 was prepared from $341(90 \mathrm{mg}, 0.31 \mathrm{mmol})$ and 3-chlorobenzylamine $(0.15 \mathrm{~mL}$, $1.2 \mathrm{mmol}$ ) in a fashion similar to the one described for compound 3. Pale solid, $111 \mathrm{mg}$, yield 91\%. ${ }^{1} \mathrm{H}-\mathrm{NMR}\left(400 \mathrm{MHz} \mathrm{CDCl}_{3}\right) \delta 8.49(\mathrm{~s}, 1 \mathrm{H}), 8.04(\mathrm{dd}, J=7.4,1.8 \mathrm{~Hz}, 1 \mathrm{H}), 7.87$ $(\mathrm{dd}, J=7.4,1.8 \mathrm{~Hz}, 1 \mathrm{H}), 7.83(\mathrm{~d}, J=8.2 \mathrm{~Hz}, 1 \mathrm{H}), 7.51-7.46(\mathrm{~m}, 2 \mathrm{H}), 7.43(\mathrm{~d}, J=8.2 \mathrm{~Hz}$, 1H), $7.39(\mathrm{~s}, 1 \mathrm{H}), 7.29-7.25(\mathrm{~m}, 3 \mathrm{H}), 7.22(\mathrm{~d}, J=7.4 \mathrm{~Hz}, 1 \mathrm{H}), 6.80(\mathrm{~d}, J=3.6 \mathrm{~Hz}, 1 \mathrm{H}), 6.29$ $(\mathrm{d}, J=3.6 \mathrm{~Hz}, 1 \mathrm{H}), 5.84(\mathrm{~s}, 2 \mathrm{H}), 5.32(\mathrm{t}, J=6.0 \mathrm{~Hz}, 1 \mathrm{H}), 4.84(\mathrm{~d}, J=6.0 \mathrm{~Hz}, 2 \mathrm{H}) ;{ }^{13} \mathrm{C}-\mathrm{NMR}$ $\left(100 \mathrm{MHz}, \mathrm{CDCl}_{3}\right) \delta 156.4,152.3,150.2,141.3,134.7,134.0,132.6,131.4,130.1,129.1,128.9$, $\left.127.9,127.8,126.9,126.7,126.2,125.9,125.5,124.3,123.3,103.1,97.8,46.0,44.7 . \mathrm{HRMS}_{(\mathrm{ESI}}{ }^{+}\right)$ $m / z$ calcd. for $\mathrm{C}_{24} \mathrm{H}_{20} \mathrm{ClN}_{4}[\mathrm{M}+\mathrm{H}]^{+}$399.1371, found 399.1365.

N-(3-Chlorobenzyl)-7-(quinolin-4-ylmethyl)-7H-pyrrolo[2,3-d]pyrimidin-4-amine (14). Compound 14 was prepared from $34 \mathrm{~m}(74 \mathrm{mg}, 0.25 \mathrm{mmol})$ and 3-chlorobenzylamine $(122 \mu \mathrm{L}$, $1.00 \mathrm{mmol}$ ) in a fashion similar to the one described for compound 3. Pale solid, $84 \mathrm{mg}$, yield $84 \%$. ${ }^{1} \mathrm{H}-\mathrm{NMR}\left(400 \mathrm{MHz}, \mathrm{CDCl}_{3}\right) \delta 8.80(\mathrm{~d}, J=4.4 \mathrm{~Hz}, 1 \mathrm{H}), 8.44(\mathrm{~s}, 1 \mathrm{H}), 8.15$ (dd, 
$J=8.4,1.2 \mathrm{~Hz}, 1 \mathrm{H}), 8.08(\mathrm{dd}, J=8.4,1.2 \mathrm{~Hz}, 1 \mathrm{H}), 7.75(\mathrm{td}, J=7.8,1.3 \mathrm{~Hz}, 1 \mathrm{H}), 7.60(\mathrm{td}$, $J=7.8,1.3 \mathrm{~Hz}, 1 \mathrm{H}), 7.40(\mathrm{~s}, 1 \mathrm{H}), 7.31-7.27(\mathrm{~m}, 3 \mathrm{H}), 6.90(\mathrm{~d}, J=3.6 \mathrm{~Hz}, 1 \mathrm{H}), 6.81(\mathrm{~d}, J=4.4 \mathrm{~Hz}$, $1 \mathrm{H}), 6.41(\mathrm{~d}, J=3.6 \mathrm{~Hz}, 1 \mathrm{H}), 5.89(\mathrm{~s}, 2 \mathrm{H}), 5.37(\mathrm{t}, J=6.0 \mathrm{~Hz}, 1 \mathrm{H}), 4.86(\mathrm{~d}, J=6.0 \mathrm{~Hz}, 2 \mathrm{H})$; ${ }^{13} \mathrm{C}-\mathrm{NMR}\left(100 \mathrm{MHz}, \mathrm{CDCl}_{3}\right) \delta 156.5,152.6,150.5(\times 2), 148.4,142.7,141.2,134.8,130.5,130.2$, 129.8, 127.9, 127.8, 127.4, 126.2, 126.0, 124.4, 122.8, 119.4, 103.1, 98.6, 44.9, 44.7. HRMS (ESI ${ }^{+}$) $m / z$ calcd. for $\mathrm{C}_{23} \mathrm{H}_{19} \mathrm{ClN}_{4}[\mathrm{M}+\mathrm{H}]^{+} 400.1323$, found 400.1311 .

4-((4-((3-Chlorobenzyl)amino)-7H-pyrrolo[2,3-d]pyrimidin-7-yl)methyl)-1-naphthonitrile (15). Compound 15 was prepared from $34 \mathrm{n}(80 \mathrm{mg}, 0.25 \mathrm{mmol})$ and 3-chlorobenzylamine $(122 \mu \mathrm{L}, 1.00 \mathrm{mmol})$ in a fashion similar to the one described for compound 3. Pale solid, $104 \mathrm{mg}$, yield $98 \% .{ }^{1} \mathrm{H}-\mathrm{NMR}\left(400 \mathrm{MHz}, \mathrm{CDCl}_{3}\right) \delta 8.43(\mathrm{~s}, 1 \mathrm{H}), 8.28(\mathrm{dd}, J=8.4,1.2 \mathrm{~Hz}, 1 \mathrm{H})$, $8.18(\mathrm{dd}, J=8.4,1.2 \mathrm{~Hz}, 1 \mathrm{H}), 7.81(\mathrm{~d}, J=7.8 \mathrm{~Hz}, 1 \mathrm{H}), 7.72(\mathrm{td}, J=7.8,1.3 \mathrm{~Hz}, 1 \mathrm{H}), 7.66(\mathrm{td}$, $J=7.8,1.3 \mathrm{~Hz}, 1 \mathrm{H}), 7.39(\mathrm{~s}, 1 \mathrm{H}), 7.29-7.26(\mathrm{~m}, 3 \mathrm{H}), 7.04(\mathrm{~d}, J=7.8 \mathrm{~Hz}, 1 \mathrm{H}), 6.85(\mathrm{~d}, J=3.6 \mathrm{~Hz}$, $1 \mathrm{H}), 6.38(\mathrm{~d}, J=3.6 \mathrm{~Hz}, 1 \mathrm{H}), 5.90(\mathrm{~s}, 2 \mathrm{H}), 5.42(\mathrm{t}, J=6.0 \mathrm{~Hz}, 1 \mathrm{H}), 4.85(\mathrm{~d}, J=6.0 \mathrm{~Hz}, 2 \mathrm{H})$; ${ }^{13} \mathrm{C}-\mathrm{NMR}\left(100 \mathrm{MHz}, \mathrm{CDCl}_{3}\right) \delta 156.5,152.6,150.3,141.1,139.0,134.7,132.6,132.4,130.7$, $130.1,128.8,128.5,127.9,127.8,126.2,125.9,124.4,124.2,123.8,117.8,110.8,103.1,98.6,45.8$, 44.7. HRMS (ESI ${ }^{+}$) $m / z$ calcd. for $\mathrm{C}_{25} \mathrm{H}_{19} \mathrm{ClN}_{5}[\mathrm{M}+\mathrm{H}]^{+} 424.1323$, found 424.1294 .

N-(3-Chlorobenzyl)-7-((2-chloroquinolin-6-yl)methyl)-7H-pyrrolo[2,3-d]pyrimidin-4-amine (16). Compound 16 was prepared from 340 (310 $\mathrm{mg}, 0.942 \mathrm{mmol})$ and 3-chlorobenzylamine $(0.46 \mathrm{~mL}, 3.78 \mathrm{mmol})$ in a fashion similar to the one described for compound 3. Pale solid, $381 \mathrm{mg}$, yield 93\%. ${ }^{1} \mathrm{H}-\mathrm{NMR}\left(400 \mathrm{MHz}, \mathrm{CDCl}_{3}\right) \delta 8.43(\mathrm{~s}, 1 \mathrm{H}), 8.01(\mathrm{~d}, J=8.6 \mathrm{~Hz}, 1 \mathrm{H}), 7.96$ $(\mathrm{d}, J=8.6 \mathrm{~Hz}, 1 \mathrm{H}), 7.60-7.56(\mathrm{~m}, 2 \mathrm{H}), 7.39(\mathrm{~s}, 1 \mathrm{H}), 7.36(\mathrm{~d}, J=8.6 \mathrm{~Hz}, 1 \mathrm{H}), 7.29-7.25(\mathrm{~m}, 3 \mathrm{H})$, $6.95(\mathrm{~d}, J=3.6 \mathrm{~Hz}, 1 \mathrm{H}), 6.39(\mathrm{~d}, J=3.6 \mathrm{~Hz}, 1 \mathrm{H}), 5.57(\mathrm{~s}, 2 \mathrm{H}), 5.42(\mathrm{t}, J=6.0 \mathrm{~Hz}, 1 \mathrm{H}), 4.85(\mathrm{~d}$, $J=6.0 \mathrm{~Hz}, 2 \mathrm{H}) ;{ }^{13} \mathrm{C}-\mathrm{NMR}\left(100 \mathrm{MHz}, \mathrm{CDCl}_{3}\right) \delta 156.4,152.5,151.0,150.4,147.5,141.2,138.9$, 136.5, 134.7, $130.1(\times 2), 129.4,127.8(\times 2), 126.9,125.9,125.8,124.3,122.9,103.1,98.4,47.8$, 44.6. HRMS $\left(\mathrm{ESI}^{+}\right) \mathrm{m} / z$ calcd. for $\mathrm{C}_{23} \mathrm{H}_{18} \mathrm{Cl}_{2} \mathrm{~N}_{5}[\mathrm{M}+\mathrm{H}]^{+}$434.0934, found 434.0910.

7-(4-Nitrobenzyl)-7H-pyrrolo[2,3-d]pyrimidin-4-amine (17). A mixture of compound 34a $(201 \mathrm{mg}, 0.696 \mathrm{mmol})$ in 1,4-dioxane $(5.0 \mathrm{~mL})$ and strong ammonia $(5.0 \mathrm{~mL})$ in a seal tube was heated at $120^{\circ} \mathrm{C}$ for $4 \mathrm{~h}$. After being allowed to cool to $\mathrm{rt}$, the reaction mixture was concentrated and the residue was purified by flash column chromatography $\left(0 \%-10 \% \mathrm{MeOH} / \mathrm{CH}_{2} \mathrm{Cl}_{2}\right)$ to afford compound 17 as a yellow solid $(109 \mathrm{mg}, 58 \%) .{ }^{1} \mathrm{H}-$ NMR $\left(400 \mathrm{MHz}\right.$, DMSO- $\left.d_{6}\right) \delta 8.16(\mathrm{~d}, J=8.7 \mathrm{~Hz}, 2 \mathrm{H}), 8.04(\mathrm{~s}, 1 \mathrm{H}), 7.38(\mathrm{~d}, J=8.7 \mathrm{~Hz}$, $2 \mathrm{H}), 7.24(\mathrm{~d}, J=3.6 \mathrm{~Hz}, 1 \mathrm{H}), 7.02(\mathrm{~s}, 2 \mathrm{H}), 6.61(\mathrm{~d}, J=3.6 \mathrm{~Hz}, 1 \mathrm{H}), 5.47(\mathrm{~s}, 2 \mathrm{H}) ;{ }^{13} \mathrm{C}-\mathrm{NMR}$ $\left(100 \mathrm{MHz}, \mathrm{DMSO}-d_{6}\right) \delta 157.7,152.1,149.8,147.0,146.2,128.4,124.5,123.9,102.6,99.6,46.8$. HRMS (ESI ${ }^{+}$) $m / z$ calcd. for $\mathrm{C}_{13} \mathrm{H}_{12} \mathrm{~N}_{5} \mathrm{O}_{2}[\mathrm{M}+\mathrm{H}]^{+} 270.0986$, found 270.0985 .

N-Benzyl-7-(4-nitrobenzyl)-7H-pyrrolo[2,3-d]pyrimidin-4-amine (18). Compound 18 was prepared from 34a $(58 \mathrm{mg}, 0.20 \mathrm{mmol})$ and benzylamine $(87 \mu \mathrm{L}, 0.80 \mathrm{mmol})$ in a fashion similar to the one described for compound 3. Yellow solid, $68 \mathrm{mg}$, yield $95 \% .{ }^{1} \mathrm{H}-\mathrm{NMR}$ $\left(400 \mathrm{MHz}, \mathrm{CDCl}_{3}\right) \delta 8.40(\mathrm{~s}, 1 \mathrm{H}), 8.15(\mathrm{~d}, J=8.7 \mathrm{~Hz}, 2 \mathrm{H}), 7.42-7.35(\mathrm{~m}, 4 \mathrm{H}), 7.33-7.28(\mathrm{~m}$, $3 \mathrm{H}), 6.90(\mathrm{~d}, J=3.6 \mathrm{~Hz}, 1 \mathrm{H}), 6.39(\mathrm{~d}, J=3.6 \mathrm{~Hz}, 1 \mathrm{H}), 5.49(\mathrm{~s}, 2 \mathrm{H}), 5.35(\mathrm{t}, J=6.0 \mathrm{~Hz}, 1 \mathrm{H})$, $4.86(\mathrm{~d}, J=6.0 \mathrm{~Hz}, 2 \mathrm{H}) ;{ }^{13} \mathrm{C}-\mathrm{NMR}\left(100 \mathrm{MHz}, \mathrm{CDCl}_{3}\right) \delta 156.6,152.7,150.4,147.7,144.9,138.8$, 129.0, 128.1, 127.9, 127.8, 124.2, 123.9, 103.1, 98.8, 47.5, 45.4. HRMS $\left(\right.$ ESI $\left.^{+}\right) \mathrm{m} / z$ calcd. for $\mathrm{C}_{20} \mathrm{H}_{18} \mathrm{~N}_{5} \mathrm{O}_{2}[\mathrm{M}+\mathrm{H}]^{+}$360.1455, found 360.1450.

$\mathrm{N}$-(2-Chlorobenzyl)-7-(4-nitrobenzyl)-7H-pyrrolo[2,3-d]pyrimidin-4-amine (19). Compound 19 was prepared from $34 \mathrm{a}(80 \mathrm{mg}, 0.28 \mathrm{mmol})$ and 2-chlorobenzylamine $(134 \mu \mathrm{L}, 1.11 \mathrm{mmol})$ in a fashion similar to the one described for compound 3. Yellow semi-solid, $108 \mathrm{mg}$, yield 99\%. ${ }^{1} \mathrm{H}-\mathrm{NMR}\left(400 \mathrm{MHz}, \mathrm{CDCl}_{3}\right) \delta 8.39(\mathrm{~s}, 1 \mathrm{H}), 8.14(\mathrm{~d}, J=8.6 \mathrm{~Hz}, 2 \mathrm{H}), 7.51-7.48(\mathrm{~m}, 1 \mathrm{H})$, $7.40-7.37(\mathrm{~m}, 1 \mathrm{H}), 7.29(\mathrm{~d}, J=8.6 \mathrm{~Hz}, 2 \mathrm{H}), 7.25-7.21(\mathrm{~m}, 2 \mathrm{H}), 6.90(\mathrm{~d}, J=3.6 \mathrm{~Hz}, 1 \mathrm{H}), 6.39$ $(\mathrm{d}, J=3.6 \mathrm{~Hz}, 1 \mathrm{H}), 5.52(\mathrm{t}, J=6.0 \mathrm{~Hz}, 1 \mathrm{H}), 5.48(\mathrm{~s}, 2 \mathrm{H}), 4.95(\mathrm{~d}, J=6.0 \mathrm{~Hz}, 2 \mathrm{H}) ;{ }^{13} \mathrm{C}-\mathrm{NMR}$ $\left(100 \mathrm{MHz}, \mathrm{CDCl}_{3}\right) \delta 156.5,152.6,150.4,147.6,144.8,136.3,133.7,130.0,129.7,129.0,128.1$, 127.2, 124.2, 124.0, 103.2, 98.8, 47.8, 43.1. HRMS $\left(\right.$ ESI $\left.^{+}\right) \mathrm{m} / z$ calcd. for $\mathrm{C}_{20} \mathrm{H}_{17} \mathrm{ClN}_{5} \mathrm{O}_{2}$ $[\mathrm{M}+\mathrm{H}]^{+}$394.1065, found 394.1064. 
N-(4-Chlorobenzyl)-7-(4-nitrobenzyl)-7H-pyrrolo[2,3-d]pyrimidin-4-amine (20). Compound 20 was prepared from $34 \mathbf{a}(80 \mathrm{mg}, 0.28 \mathrm{mmol})$ and 4-chlorobenzylamine $(135 \mu \mathrm{L}, 1.11 \mathrm{mmol})$ in a fashion similar to the one described for compound 3. Yellow solid, $109 \mathrm{mg}$, quantitative yield. ${ }^{1} \mathrm{H}-\mathrm{NMR}\left(400 \mathrm{MHz}, \mathrm{CDCl}_{3}\right) \delta 8.39(\mathrm{~s}, 1 \mathrm{H}), 8.15(\mathrm{~d}, J=8.6 \mathrm{~Hz}, 2 \mathrm{H}), 7.33-7.29(\mathrm{~m}, 6 \mathrm{H})$, $6.91(\mathrm{~d}, J=3.6 \mathrm{~Hz}, 1 \mathrm{H}), 6.39(\mathrm{~d}, J=3.6 \mathrm{~Hz}, 1 \mathrm{H}), 5.49(\mathrm{~s}, 2 \mathrm{H}), 5.34(\mathrm{t}, J=6.0 \mathrm{~Hz}, 1 \mathrm{H}), 4.83$ $(\mathrm{d}, J=6.0 \mathrm{~Hz}, 2 \mathrm{H}) ;{ }^{13} \mathrm{C}-\mathrm{NMR}\left(100 \mathrm{MHz}, \mathrm{CDCl}_{3}\right) \delta 156.4,152.6,150.4,147.7,144.8,137.5$, $133.5,129.2,129.0,128.1,124.2,124.1,103.1,98.7,47.5,44.6$. HRMS $\left(\mathrm{ESI}^{+}\right) \mathrm{m} / \mathrm{z}$ calcd. for $\mathrm{C}_{20} \mathrm{H}_{17} \mathrm{ClN}_{5} \mathrm{O}_{2}[\mathrm{M}+\mathrm{H}]^{+} 394.1065$, found 394.1062.

N-(2,3-Dichlorobenzyl)-7-(4-nitrobenzyl)-7H-pyrrolo[2,3-d]pyrimidin-4-amine (21). Compound 21 was prepared from 34a $(58 \mathrm{mg}, 0.20 \mathrm{mmol})$ and 2,3-dichlorobenzylamine $(0.11 \mathrm{~mL}$, $0.82 \mathrm{mmol}$ ) in a fashion similar to the one described for compound 3 . Yellowish solid, $86 \mathrm{mg}$, quantitative yield. ${ }^{1} \mathrm{H}-\mathrm{NMR}\left(400 \mathrm{MHz}^{\mathrm{CDCl}}\right)_{3} \delta 8.38(\mathrm{~s}, 1 \mathrm{H}), 8.15(\mathrm{~d}, \mathrm{~J}=8.6 \mathrm{~Hz}$, $2 \mathrm{H}), 7.43-7.38(\mathrm{~m}, 2 \mathrm{H}), 7.31(\mathrm{~d}, J=8.6 \mathrm{~Hz}, 2 \mathrm{H}), 7.17(\mathrm{t}, J=7.7 \mathrm{~Hz}, 1 \mathrm{H}), 6.92(\mathrm{~d}, J=3.6 \mathrm{~Hz}$, $1 \mathrm{H}), 6.39(\mathrm{~d}, J=3.6 \mathrm{~Hz}, 1 \mathrm{H}), 5.54(\mathrm{t}, J=6.0 \mathrm{~Hz}, 1 \mathrm{H}), 5.48(\mathrm{~s}, 2 \mathrm{H}), 4.96(\mathrm{~d}, J=6.0 \mathrm{~Hz}, 2 \mathrm{H}) ;{ }^{13} \mathrm{C}-$ NMR $\left(100 \mathrm{MHz} \mathrm{CDCl}_{3}\right) \delta 156.4,152.5,150.4,147.7,144.8,138.8,133.4,131.8,129.7,128.1$, $127.9,127.5,124.2(\times 2), 103.2,98.6,47.5,43.7$. HRMS $\left(\mathrm{ESI}^{+}\right) \mathrm{m} / z$ calcd. for $\mathrm{C}_{20} \mathrm{H}_{16} \mathrm{Cl}_{2} \mathrm{~N}_{5} \mathrm{O}_{2}$ $[\mathrm{M}+\mathrm{H}]^{+} 428.0676$, found 428.0660 .

$N$-(2,5-Dichlorobenzyl)-7-(4-nitrobenzyl)-7H-pyrrolo[2,3-d]pyrimidin-4-amine (22). Compound 22 was prepared from 34a $(58 \mathrm{mg}, 0.20 \mathrm{mmol})$ and 2,5-dichlorobenzylamine $(0.11 \mathrm{~mL}$, $0.82 \mathrm{mmol})$ in a fashion similar to the one described for compound 3. Yellowish solid, $83 \mathrm{mg}$, yield 96\%. ${ }^{1} \mathrm{H}-\mathrm{NMR}\left(400 \mathrm{MHz}, \mathrm{CDCl}_{3}\right) \delta 8.41(\mathrm{~s}, 1 \mathrm{H}), 8.16(\mathrm{~d}, J=8.6 \mathrm{~Hz}, 2 \mathrm{H}), 7.48(\mathrm{~d}$, $J=2.4 \mathrm{~Hz}, 1 \mathrm{H}), 7.34-7.30(\mathrm{~m}, 3 \mathrm{H}), 7.20(\mathrm{dd}, J=8.4,2.4 \mathrm{~Hz}, 1 \mathrm{H}), 6.93(\mathrm{~d}, J=3.6 \mathrm{~Hz}, 1 \mathrm{H}), 6.40$ $(\mathrm{d}, J=3.6 \mathrm{~Hz}, 1 \mathrm{H}), 5.51(\mathrm{t}, J=6.0 \mathrm{~Hz}, 1 \mathrm{H}), 5.49(\mathrm{~s}, 2 \mathrm{H}), 4.92(\mathrm{~d}, J=6.0 \mathrm{~Hz}, 2 \mathrm{H}) ;{ }^{13} \mathrm{C}-\mathrm{NMR}$ $\left(100 \mathrm{MHz}_{\mathrm{CDCl}}\right) \delta 156.3,152.5,150.4,147.7,144.7,138.2,133.1,131.7,130.8,129.6,128.9$, $128.1,124.2(\times 2), 103.2,98.6,47.5,42.7$. HRMS $\left(\mathrm{ESI}^{+}\right) \mathrm{m} / z$ calcd. for $\mathrm{C}_{20} \mathrm{H}_{16} \mathrm{Cl}_{2} \mathrm{~N}_{5} \mathrm{O}_{2}$ $[\mathrm{M}+\mathrm{H}]^{+} 428.0676$, found 428.0670 .

N-(3,4-Dichlorobenzyl)-7-(4-nitrobenzyl)-7H-pyrrolo[2,3-d]pyrimidin-4-amine (23). Compound 23 was prepared from 34a $(46 \mathrm{mg}, 0.16 \mathrm{mmol})$ and 3,4-dichlorobenzylamine (115 $\mathrm{mg}$, $0.653 \mathrm{mmol}$ ) in a fashion similar to the one described for compound 3. Yellowish solid, $65 \mathrm{mg}$, yield 95\%. ${ }^{1} \mathrm{H}-\mathrm{NMR}\left(400 \mathrm{MHz}, \mathrm{CDCl}_{3}\right) \delta 8.39(\mathrm{~s}, 1 \mathrm{H}), 8.16(\mathrm{~d}, \mathrm{~J}=8.6 \mathrm{~Hz}, 2 \mathrm{H}), 7.49(\mathrm{~d}$, $J=2.3 \mathrm{~Hz}, 1 \mathrm{H}), 7.41(\mathrm{~d}, J=8.2 \mathrm{~Hz}, 1 \mathrm{H}), 7.32(\mathrm{~d}, J=8.6 \mathrm{~Hz}, 2 \mathrm{H}), 7.14(\mathrm{dd}, J=8.4,2.3 \mathrm{~Hz}, 1 \mathrm{H})$, $6.94(\mathrm{~d}, J=3.6 \mathrm{~Hz}, 1 \mathrm{H}), 6.40(\mathrm{~d}, J=3.6 \mathrm{~Hz}, 1 \mathrm{H}), 5.50(\mathrm{~s}, 2 \mathrm{H}), 5.40(\mathrm{t}, J=6.0 \mathrm{~Hz}, 1 \mathrm{H}), 4.83(\mathrm{~d}$, $J=6.0 \mathrm{~Hz}, 2 \mathrm{H}) ;{ }^{13} \mathrm{C}-\mathrm{NMR}\left(100 \mathrm{MHz}, \mathrm{CDCl}_{3}\right) \delta 156.3,152.5,150.4,147.7,144.7,138.1,133.0$, 132.0, 130.8, 129.6, 128.1, 127.1, 124.3, 124.2, 103.1, 98.6, 47.5, 44.1. HRMS (ESI $\left.{ }^{+}\right) \mathrm{m} / z$ calcd. for $\mathrm{C}_{20} \mathrm{H}_{16} \mathrm{Cl}_{2} \mathrm{~N}_{5} \mathrm{O}_{2}[\mathrm{M}+\mathrm{H}]^{+} 428.0676$, found 428.0665 .

N-(Naphthalen-1-ylmethyl)-7-(4-nitrobenzyl)-7H-pyrrolo[2,3-d]pyrimidin-4-amine (24). Compound 24 was prepared from 34a $(58 \mathrm{mg}, 0.20 \mathrm{mmol})$ and naphthalen-1-ylmethanamine $(0.12 \mathrm{~mL}, 0.82 \mathrm{mmol})$ in a fashion similar to the one described for compound 3 . Yellowish solid, $63 \mathrm{mg}$, yield 76\%. ${ }^{1} \mathrm{H}-\mathrm{NMR}\left(400 \mathrm{MHz}^{\mathrm{CDCl}} 3\right) \delta 8.48(\mathrm{~s}, 1 \mathrm{H}), 8.15(\mathrm{~d}, J=8.8 \mathrm{~Hz}, 2 \mathrm{H})$, 8.13-8.11 (m, 1H), 7.92-7.89 (m, 1H), $7.85(\mathrm{~d}, J=8.2 \mathrm{~Hz}, 1 \mathrm{H}), 7.58-7.51(\mathrm{~m}, 3 \mathrm{H}), 7.46$ (dd, $J=8.2,6.8 \mathrm{~Hz}, 1 \mathrm{H}), 7.31(\mathrm{~d}, J=8.8 \mathrm{~Hz}, 2 \mathrm{H}), 6.89(\mathrm{~d}, J=3.6 \mathrm{~Hz}, 1 \mathrm{H}), 6.32(\mathrm{~d}, J=3.6 \mathrm{~Hz}, 1 \mathrm{H})$, 5.49 (s, 2H), 5.30-5.28 (m, 3H); ${ }^{13} \mathrm{C}-\mathrm{NMR}\left(100 \mathrm{MHz}, \mathrm{CDCl}_{3}\right) \delta 156.4,152.7,150.3,147.7,144.9$, 134.1, 133.9, 131.7, 129.0, 128.8, 128.1, 126.8 (×2), 126.2, 125.6, 124.2, 123.9, 123.7, 103.1, 98.8, 47.5, 43.7. HRMS $\left(\mathrm{ESI}^{+}\right) \mathrm{m} / z$ calcd. for $\mathrm{C}_{24} \mathrm{H}_{20} \mathrm{~N}_{5} \mathrm{O}_{2}[\mathrm{M}+\mathrm{H}]^{+} 410.1612$, found 410.1611 .

4-((4-((3-Methylbenzyl)amino)-7H-pyrrolo[2,3-d]pyrimidin-7-yl)methyl)benzonitrile (25). Compound 25 was prepared from $34 \mathrm{~g}(45 \mathrm{mg}, 0.17 \mathrm{mmol})$ and 3-methylbenzylamine $(85 \mu \mathrm{L}$, $0.68 \mathrm{mmol}$ ) in a fashion similar to the one described for compound 3. Yellowish semi-solid, $56 \mathrm{mg}$, yield 95\%. ${ }^{1} \mathrm{H}-\mathrm{NMR}\left(400 \mathrm{MHz}, \mathrm{CDCl}_{3}\right) \delta 8.40(\mathrm{~s}, 1 \mathrm{H}), 7.58(\mathrm{~d}, J=8.4 \mathrm{~Hz}, 2 \mathrm{H})$, $7.27-7.18(\mathrm{~m}, 5 \mathrm{H}), 7.12(\mathrm{~d}, J=7.4 \mathrm{~Hz}, 1 \mathrm{H}), 6.88(\mathrm{~d}, J=3.6 \mathrm{~Hz}, 1 \mathrm{H}), 6.38(\mathrm{~d}, J=3.6 \mathrm{~Hz}, 1 \mathrm{H})$, $5.44(\mathrm{~s}, 2 \mathrm{H}), 5.32(\mathrm{t}, J=6.0 \mathrm{~Hz}, 1 \mathrm{H}), 4.81(\mathrm{~d}, J=6.0 \mathrm{~Hz}, 2 \mathrm{H}), 2.35(\mathrm{~s}, 3 \mathrm{H}) ;{ }^{13} \mathrm{C}-\mathrm{NMR}(100 \mathrm{MHz}$, $\left.\mathrm{CDCl}_{3}\right) \delta 156.5,152.6,150.3,142.9,138.7$ (×2), 132.7, 128.8, 128.7, 128.5, 127.9, 125.0, 123.9, 
118.7, $111.8,103.0,98.8,47.7,45.5,21.5$. HRMS $\left(\mathrm{ESI}^{+}\right) \mathrm{m} / z$ calcd. for $\mathrm{C}_{22} \mathrm{H}_{20} \mathrm{~N}_{5}[\mathrm{M}+\mathrm{H}]^{+}$ 354.1713 , found 354.1712 .

4-((4-((2-Chlorobenzyl)amino)-7H-pyrrolo[2,3-d]pyrimidin-7-yl)methyl)benzonitrile (26). Compound 26 was prepared from $34 \mathrm{~g}(45 \mathrm{mg}, 0.17 \mathrm{mmol})$ and 2-chlorobenzylamine $(81 \mu \mathrm{L}$, $0.67 \mathrm{mmol}$ ) in a fashion similar to the one described for compound 3. Pale solid, $55 \mathrm{mg}$, yield $88 \%$. ${ }^{1} \mathrm{H}-\mathrm{NMR}\left(400 \mathrm{MHz}, \mathrm{CDCl}_{3}\right) \delta 8.39(\mathrm{~s}, 1 \mathrm{H}), 7.58(\mathrm{~d}, J=8.6 \mathrm{~Hz}, 2 \mathrm{H}), 7.49(\mathrm{dd}$, $J=7.4,3.0 \mathrm{~Hz}, 1 \mathrm{H}), 7.39(\mathrm{dd}, J=7.4,3.0 \mathrm{~Hz}, 1 \mathrm{H}), 7.26-7.22(\mathrm{~m}, 4 \mathrm{H}), 6.86(\mathrm{~d}, J=3.6 \mathrm{~Hz}$, $1 \mathrm{H}), 6.38(\mathrm{~d}, J=3.6 \mathrm{~Hz}, 1 \mathrm{H}), 5.47(\mathrm{t}, J=6.0 \mathrm{~Hz}, 1 \mathrm{H}), 5.44(\mathrm{~s}, 2 \mathrm{H}), 4.95(\mathrm{~d}, J=6.0 \mathrm{~Hz}, 2 \mathrm{H})$; ${ }^{13} \mathrm{C}-\mathrm{NMR}\left(100 \mathrm{MHz}, \mathrm{CDCl}_{3}\right) \delta 156.5,152.6,150.4,142.9,136.3,133.7,132.7,130.0,129.8$, 129.0, 127.9, 127.2, 124.1, 118.7, 111.8, 103.1, 98.6, 47.7, 43.1. HRMS (ESI $\left.{ }^{+}\right) \mathrm{m} / z$ calcd. for $\mathrm{C}_{21} \mathrm{H}_{17} \mathrm{ClN}_{5}[\mathrm{M}+\mathrm{H}]^{+}$374.1167, found 374.1167.

4-((4-((2,3-Dichlorobenzyl)amino)-7H-pyrrolo[2,3-d]pyrimidin-7-yl)methyl)benzonitrile (27). Compound 27 was prepared from $34 \mathrm{~g}(45 \mathrm{mg}, 0.17 \mathrm{mmol})$ and 2,3-dichlorobenzylamine (118 mg, $0.67 \mathrm{mmol}$ ) in a fashion similar to the one described for compound 3. Pale solid, $58 \mathrm{mg}$, yield 85\%. ${ }^{1} \mathrm{H}-\mathrm{NMR}\left(400 \mathrm{MHz}, \mathrm{CDCl}_{3}\right) \delta 8.37(\mathrm{~s}, 1 \mathrm{H}), 7.58(\mathrm{~d}, J=8.4 \mathrm{~Hz}, 2 \mathrm{H}), 7.40(\mathrm{dd}$, $J=7.8,1.7 \mathrm{~Hz}, 2 \mathrm{H}), 7.24(\mathrm{~d}, J=8.4 \mathrm{~Hz}, 2 \mathrm{H}), 7.16(\mathrm{t}, J=7.8 \mathrm{~Hz}, 1 \mathrm{H}), 6.90(\mathrm{~d}, J=3.6 \mathrm{~Hz}$, $1 \mathrm{H}), 6.38(\mathrm{~d}, J=3.6 \mathrm{~Hz}, 1 \mathrm{H}), 5.54(\mathrm{t}, J=6.0 \mathrm{~Hz}, 1 \mathrm{H}), 5.44(\mathrm{~s}, 2 \mathrm{H}), 4.96(\mathrm{~d}, J=6.0 \mathrm{~Hz}, 2 \mathrm{H})$; ${ }^{13} \mathrm{C}-\mathrm{NMR}\left(100 \mathrm{MHz}, \mathrm{CDCl}_{3}\right) \delta 156.4,152.5,150.4,142.8,138.8,133.4,132.7,131.8,129.6$, 128.0, 127.9, 127.6, 124.2, 118.7, 111.9, 103.2, 98.5, 47.7, 43.6. HRMS $\left(\mathrm{ESI}^{+}\right) \mathrm{m} / \mathrm{z}$ calcd. for $\mathrm{C}_{21} \mathrm{H}_{16} \mathrm{Cl}_{2} \mathrm{~N}_{5}[\mathrm{M}+\mathrm{H}]^{+}$408.0777, found 408.0777.

4-((4-((2,5-Dichlorobenzyl)amino)-7H-pyrrolo[2,3-d]pyrimidin-7-yl)methyl)benzonitrile (28). Compound 28 was prepared from $34 \mathrm{~g}(45 \mathrm{mg}, 0.17 \mathrm{mmol})$ and 2,5-dichlorobenzylamine $(90 \mu \mathrm{L}$, $0.67 \mathrm{mmol}$ ) in a fashion similar to the one described for compound 3. Pale solid, $54 \mathrm{mg}$, yield 79\%. ${ }^{1} \mathrm{H}-\mathrm{NMR}\left(400 \mathrm{MHz}, \mathrm{CDCl}_{3}\right) \delta 8.39(\mathrm{~s}, 1 \mathrm{H}), 7.59(\mathrm{~d}, J=8.4 \mathrm{~Hz}, 2 \mathrm{H}), 7.48(\mathrm{~d}$, $J=2.5 \mathrm{~Hz}, 1 \mathrm{H}), 7.32(\mathrm{~d}, J=8.6 \mathrm{~Hz}, 1 \mathrm{H}), 7.26(\mathrm{~d}, J=8.4 \mathrm{~Hz}, 2 \mathrm{H}), 7.20(\mathrm{dd}, J=8.6,2.5 \mathrm{~Hz}, 1 \mathrm{H})$, $6.91(\mathrm{~d}, J=3.6 \mathrm{~Hz}, 1 \mathrm{H}), 6.39(\mathrm{~d}, J=3.6 \mathrm{~Hz}, 1 \mathrm{H}), 5.48(\mathrm{t}, J=6.0 \mathrm{~Hz}, 1 \mathrm{H}), 5.44(\mathrm{~s}, 2 \mathrm{H}), 4.92(\mathrm{~d}$, $J=6.0 \mathrm{~Hz}, 2 \mathrm{H}) ;{ }^{13} \mathrm{C}-\mathrm{NMR}\left(100 \mathrm{MHz}, \mathrm{CDCl}_{3}\right) \delta 156.3,152.5,150.4,142.8,138.3,133.1,132.8$, 131.7, 130.8, 129.6, 128.9, 128.0, 124.3, 118.7, 111.9, 103.2, 98.5, 47.7, 42.7. HRMS (ESI $\left.{ }^{+}\right) \mathrm{m} / z$ calcd. for $\mathrm{C}_{21} \mathrm{H}_{16} \mathrm{Cl}_{2} \mathrm{~N}_{5}[\mathrm{M}+\mathrm{H}]^{+} 408.0777$, found 408.0777 .

6-Chloro-9-(4-nitrobenzyl)-9H-purine (36a). To a suspension of 6-chloropurine (35, $309 \mathrm{mg}$, $2.00 \mathrm{mmol})$ in anhydrous $\mathrm{CH}_{3} \mathrm{CN}(20 \mathrm{~mL})$ were added $\mathrm{K}_{2} \mathrm{CO}_{3}(830 \mathrm{mg}, 6.00 \mathrm{mmol})$ and 4 nitrobenzyl bromide (516 mg, $2.39 \mathrm{mmol})$ [14,15]. The resulting mixture was allowed to stir at $\mathrm{rt}$ for $22 \mathrm{~h}$ and concentrated. The residue was suspended in $\mathrm{MeOH}(10 \mathrm{~mL})$ and poured into stirring water $(60 \mathrm{~mL})$. The precipitate was filtered, washed with water and dried. The residue was purified by flash column chromatography $(10 \%-100 \% \mathrm{EtOAc} / \mathrm{hexanes})$ to afford compound 36a as a white solid (354 mg, 61\%). ${ }^{1} \mathrm{H}-\mathrm{NMR}\left(400 \mathrm{MHz}, \mathrm{CDCl}_{3}\right) \delta 8.78$ $(\mathrm{s}, 1 \mathrm{H}), 8.23(\mathrm{~d}, J=8.8 \mathrm{~Hz}, 2 \mathrm{H}), 8.17(\mathrm{~s}, 1 \mathrm{H}), 7.48(\mathrm{~d}, J=8.8 \mathrm{~Hz}, 2 \mathrm{H}), 5.58(\mathrm{~s}, 2 \mathrm{H}) ;{ }^{13} \mathrm{C}-\mathrm{NMR}$ $\left(100 \mathrm{MHz}, \mathrm{CDCl}_{3}\right) \delta 152.6,151.9,151.8,148.3,144.7,141.6,131.7,128.7,124.6,47.2$. HRMS $\left(\mathrm{ESI}^{+}\right) \mathrm{m} / z$ calcd. for $\mathrm{C}_{12} \mathrm{H}_{9} \mathrm{ClN}_{5} \mathrm{O}_{2}[\mathrm{M}+\mathrm{H}]^{+} 290.0439$, found 290.0437 .

4-((6-Chloro-9H-purin-9-yl)methyl)benzonitrile (36b). Compound $\mathbf{3 6} \mathbf{b}$ was prepared from 6-chloropurine ( $35,155 \mathrm{mg}, 1.00 \mathrm{mmol})$ and 4-cyanobenzyl bromide ( $235 \mathrm{mg}, 1.20 \mathrm{mmol})$ in a fashion similar to the one described for compound 36a [15]. White solid, $171 \mathrm{mg}$, yield $63 \% .{ }^{1} \mathrm{H}-\mathrm{NMR}\left(400 \mathrm{MHz}, \mathrm{CDCl}_{3}\right) \delta 8.76(\mathrm{~s}, 1 \mathrm{H}), 8.15(\mathrm{~s}, 1 \mathrm{H}), 7.65(\mathrm{~d}, J=8.6 \mathrm{~Hz}, 2 \mathrm{H}), 7.40(\mathrm{~d}$, $J=8.8 \mathrm{~Hz}, 2 \mathrm{H}), 5.52(\mathrm{~s}, 2 \mathrm{H}) ;{ }^{13} \mathrm{C}-\mathrm{NMR}\left(100 \mathrm{MHz}, \mathrm{CDCl}_{3}\right) \delta 152.5,151.9,151.7,144.8,139.8$, 133.1, 131.7, 128.5, 118.1, 113.1, 47.4. HRMS $\left(\mathrm{ESI}^{+}\right) \mathrm{m} / z$ calcd. for $\mathrm{C}_{13} \mathrm{H}_{9} \mathrm{ClN}_{5}[\mathrm{M}+\mathrm{H}]^{+}$ 270.0541, found 270.0543 .

$\mathrm{N}$-(3-Chlorobenzyl)-9-(4-nitrobenzyl)-9H-purin-6-amine (29). Compound 29 was prepared from 36a $(72 \mathrm{mg}, 0.25 \mathrm{mmol})$ and 3-chlorobenzylamine $(122 \mu \mathrm{L}, 1.00 \mathrm{mmol})$ in a fashion similar to the one described for compound 3. Pale solid, $93 \mathrm{mg}$, yield $95 \% .{ }^{1} \mathrm{H}-\mathrm{NMR}$ $\left(400 \mathrm{MHz}, \mathrm{CDCl}_{3}\right) \delta 8.42(\mathrm{~s}, 1 \mathrm{H}), 8.20(\mathrm{~d}, J=8.6 \mathrm{~Hz}, 2 \mathrm{H}), 7.71(\mathrm{~s}, 1 \mathrm{H}), 7.42(\mathrm{~d}, J=8.6 \mathrm{~Hz}, 2 \mathrm{H})$, $7.37(\mathrm{~s}, 1 \mathrm{H}), 7.25-7.23(\mathrm{~m}, 3 \mathrm{H}), 6.40(\mathrm{t}, J=6.0 \mathrm{~Hz}, 1 \mathrm{H}), 5.47(\mathrm{~s}, 2 \mathrm{H}), 4.88(\mathrm{~s}, 2 \mathrm{H}) ;{ }^{13} \mathrm{C}-\mathrm{NMR}$ $\left(100 \mathrm{MHz}, \mathrm{CDCl}_{3}\right) \delta 154.9,153.8,149.7,148.0,142.9,140.8,139.6,134.7,130.1,128.5,127.8$ 
(×2), 125.9, 125.4, 119.8, 46.5, 44.1. HRMS $\left(\mathrm{ESI}^{+}\right) \mathrm{m} / z$ calcd. for $\mathrm{C}_{19} \mathrm{H}_{16} \mathrm{ClN}_{6} \mathrm{O}_{2}[\mathrm{M}+\mathrm{H}]^{+}$ 395.1018 , found 395.1002 .

4-((6-((3-Chlorobenzyl)amino)-9H-purin-9-yl)methyl)benzonitrile (30). Compound 30 was prepared from $36 \mathbf{b}(49 \mathrm{mg}, 0.18 \mathrm{mmol})$ and 3-chlorobenzylamine $(88 \mu \mathrm{L}, 0.72 \mathrm{mmol})$ in a fashion similar to the one described for compound 3. Pale solid, $51 \mathrm{mg}$, yield $75 \%$. ${ }^{1} \mathrm{H}-$ $\operatorname{NMR}\left(400 \mathrm{MHz}, \mathrm{CDCl}_{3}\right) \delta 8.42(\mathrm{~s}, 1 \mathrm{H}), 7.70(\mathrm{~s}, 1 \mathrm{H}), 7.64(\mathrm{~d}, J=8.6 \mathrm{~Hz}, 2 \mathrm{H}), 7.37-7.35(\mathrm{~m}$, $3 \mathrm{H}), 7.25-7.23(\mathrm{~m}, 3 \mathrm{H}), 6.36(\mathrm{t}, J=6.0 \mathrm{~Hz}, 1 \mathrm{H}), 5.42(\mathrm{~s}, 2 \mathrm{H}), 4.88(\mathrm{~s}, 2 \mathrm{H}) ;{ }^{13} \mathrm{C}-\mathrm{NMR}(100 \mathrm{MHz}$, $\left.\mathrm{CDCl}_{3}\right) \delta 154.9,153.8,149.7,141.0,140.8,139.6,134.7,133.0,130.1,128.3,127.8(\times 2), 125.9$, $119.8,118.4,112.6,46.8,44.1$. HRMS (ESI+) $m / z$ calcd. for $\mathrm{C}_{20} \mathrm{H}_{16} \mathrm{ClN}_{6}[\mathrm{M}+\mathrm{H}]^{+} 375.1119$, found 375.1119 .

4-Chloro-1-(4-nitrobenzyl)-1H-pyrazolo[3,4-d]pyrimidine (38a). A mixture of 4-chloropyrazolo [3,4-d]pyrimidine (37, $155 \mathrm{mg}, 1.00 \mathrm{mmol}), 4$-nitrobenzyl bromide (259 mg, $1.20 \mathrm{mmol}$ ) and $\mathrm{Et}_{3} \mathrm{~N}(0.14 \mathrm{~mL}, 1.00 \mathrm{mmol})$ in DMF $(10 \mathrm{~mL})$ was allowed to stir at $\mathrm{rt}$ for $24 \mathrm{~h}$. The volume of the reaction mixture was reduced to about $3 \mathrm{~mL}$ and water $(30 \mathrm{~mL})$ was added while stirred. The precipitate was filtered, washed with water and dried. The resulting residue was purified by flash column chromatography ( $5 \%-60 \%$ and then $80 \%$ EtOAc/hexanes) to afford compound $38 \mathrm{a}$ as a pale solid $(77 \mathrm{mg}, 26 \%) .{ }^{1} \mathrm{H}-\mathrm{NMR}\left(400 \mathrm{MHz}, \mathrm{DMSO}-d_{6}\right) \delta$ $8.92(\mathrm{~s}, 1 \mathrm{H}), 8.58(\mathrm{~s}, 1 \mathrm{H}), 8.18(\mathrm{~d}, J=8.6 \mathrm{~Hz}, 2 \mathrm{H}), 7.50(\mathrm{~d}, J=8.6 \mathrm{~Hz}, 2 \mathrm{H}), 5.88(\mathrm{~s}, 2 \mathrm{H})$; ${ }^{13} \mathrm{C}-\mathrm{NMR}\left(100 \mathrm{MHz}\right.$, DMSO- $\left.d_{6}\right) \delta 155.1,153.9,153.1,147.0,143.7,133.1,128.8,123.8,113.2$, 49.9. HRMS (ESI ${ }^{-}$) $m / z$ calcd. for $\mathrm{C}_{12} \mathrm{H}_{7} \mathrm{ClN}_{5} \mathrm{O}_{2}[\mathrm{M}-\mathrm{H}]^{-}$288.0294, found 288.0298.

4-((4-Chloro-1H-pyrazolo[3,4-d]pyrimidin-1-yl)methyl)benzonitrile (38b). Compound $\mathbf{3 8 b}$ was prepared from 4-chloropyrazolo[3,4-d]pyrimidine $(37,155 \mathrm{mg}, 1.00 \mathrm{mmol})$ and 4-cyanobenzyl bromide $(235 \mathrm{mg}, 1.20 \mathrm{mmol})$ in a fashion similar to the one described for compound $38 \mathrm{a}$. White solid, $69 \mathrm{mg}$, yield $26 \% .{ }^{1} \mathrm{H}-\mathrm{NMR}\left(400 \mathrm{MHz}\right.$, DMSO- $\left.d_{6}\right) \delta 8.91(\mathrm{~s}, 1 \mathrm{H}), 8.56(\mathrm{~s}, 1 \mathrm{H})$, $7.80(\mathrm{~d}, J=8.6 \mathrm{~Hz}, 2 \mathrm{H}), 7.42(\mathrm{~d}, J=8.6 \mathrm{~Hz}, 2 \mathrm{H}), 5.82(\mathrm{~s}, 2 \mathrm{H}) ;{ }^{13} \mathrm{C}-\mathrm{NMR}\left(100 \mathrm{MHz}\right.$, DMSO- $\left.d_{6}\right)$ $\delta$ 155.0, 153.9, 153.1, 141.8, 133.0, 132.6, 128.5, 118.5, 113.2, 110.7, 50.1. HRMS (ESI $\left.{ }^{-}\right) \mathrm{m} / z$ calcd. for $\mathrm{C}_{13} \mathrm{H}_{7} \mathrm{ClN}_{5}[\mathrm{M}-\mathrm{H}]^{-}$268.0395, found 268.0405.

N-(3-Chlorobenzyl)-1-(4-nitrobenzyl)-1H-pyrazolo[3,4-d]pyrimidin-4-amine (31). Compound 31 was prepared from $38 \mathrm{a}(52 \mathrm{mg}, 0.18 \mathrm{mmol})$ and 3-chlorobenzylamine $(88 \mu \mathrm{L}, 0.72 \mathrm{mmol})$ in a fashion similar to the one described for compound 3. Tan solid, $70 \mathrm{mg}$, yield $98 \%$. ${ }^{1} \mathrm{H}-\mathrm{NMR}\left(400 \mathrm{MHz}, \mathrm{CDCl}_{3}\right) \delta 8.44(\mathrm{~s}, 1 \mathrm{H}), 8.16(\mathrm{~d}, J=8.6 \mathrm{~Hz}, 2 \mathrm{H}), 7.89(\mathrm{~s}, 1 \mathrm{H}), 7.46(\mathrm{~d}$, $J=8.6 \mathrm{~Hz}, 2 \mathrm{H}), 7.37(\mathrm{~s}, 1 \mathrm{H}), 7.30-7.27(\mathrm{~m}, 3 \mathrm{H}), 5.84(\mathrm{~s}, 1 \mathrm{H}), 5.67(\mathrm{~s}, 2 \mathrm{H}), 4.85(\mathrm{~d}, J=6.0 \mathrm{~Hz}$, 2H); ${ }^{13} \mathrm{C}-\mathrm{NMR}\left(100 \mathrm{MHz}, \mathrm{CDCl}_{3}\right) \delta$ 156.5, 153.8, 147.7, 143.7, 139.7, 135.0, 131.3, 130.4, 128.9, $128.2,128.0,127.8,126.0,125.9,124.1,50.1,44.5$. HRMS $\left(\mathrm{ESI}^{+}\right) \mathrm{m} / z$ calcd. for $\mathrm{C}_{19} \mathrm{H}_{16} \mathrm{ClN}_{6} \mathrm{O}_{2}$ $[\mathrm{M}+\mathrm{H}]^{+}$395.0995, found 395.0996.

4-((4-((3-Chlorobenzyl)amino)-1H-pyrazolo[3,4-d]pyrimidin-1-yl)methyl)benzonitrile (32). Compound 32 was prepared from $38 \mathbf{b}(49 \mathrm{mg}, 0.18 \mathrm{mmol})$ and 3-chlorobenzylamine $(88 \mu \mathrm{L}$, $0.72 \mathrm{mmol}$ ) in a fashion similar to the one described for compound 3. Pale solid, $65 \mathrm{mg}$, yield 95\%. ${ }^{1} \mathrm{H}-\mathrm{NMR}\left(400 \mathrm{MHz}, \mathrm{CDCl}_{3}\right) \delta 8.43(\mathrm{~s}, 1 \mathrm{H}), 7.88(\mathrm{~s}, 1 \mathrm{H}), 7.59(\mathrm{~d}, J=8.6 \mathrm{~Hz}, 2 \mathrm{H})$, $7.39(\mathrm{~d}, J=8.6 \mathrm{~Hz}, 2 \mathrm{H}), 7.37(\mathrm{~s}, 1 \mathrm{H}), 7.30-7.27(\mathrm{~m}, 3 \mathrm{H}), 5.79(\mathrm{~s}, 1 \mathrm{H}), 5.67(\mathrm{~s}, 2 \mathrm{H}), 4.84(\mathrm{~d}$, $J=6.0 \mathrm{~Hz}, 2 \mathrm{H}) ;{ }^{13} \mathrm{C}-\mathrm{NMR}\left(100 \mathrm{MHz}, \mathrm{CDCl}_{3}\right) \delta 156.4,153.8,147.5,141.8,139.8,135.0,132.7$, 130.3, 128.7, 128.2, 128.0, 127.8, 126.0, 125.8, 118.7, 112.0, 50.4, 45.1. HRMS (ESI $\left.{ }^{+}\right) \mathrm{m} / z$ calcd. for $\mathrm{C}_{20} \mathrm{H}_{16} \mathrm{ClN}_{6}[\mathrm{M}+\mathrm{H}]^{+}$375.1119, found 375.1113 .

\subsection{Cell Lines and Virus Stocks}

The hepatocyte-derived cellular carcinoma cell line Huh7 was used for ZIKV and DENV studies. Huh7 cells were maintained in Minimum Essential Medium (MEM) supplemented with $10 \%$ fetal bovine serum (FBS), $100 \mathrm{IU}$ streptomycin/penicillin per $\mathrm{mL}$, $1 \mathrm{mM}$ sodium pyruvate, $1 \times$ non-essential amino acids, $1 \times$ Glutamax (Gibco Life Technologies, Grand Island, NY, USA) and $10 \mu \mathrm{g} / \mathrm{mL}$ plasmocin (InvivoGen, San Diego, CA, USA). Vero (African green monkey kidney) cells were used to perform plaque assays for all viruses in this study. Vero cells were maintained in Dulbeco's Modified Eagle 
Medium (DMEM) supplemented with 10\% FBS, 100 IU streptomycin/penicillin per mL and $10 \mu \mathrm{g} / \mathrm{mL}$ plasmocin (InvivoGen). DENV-2 New Guinea C strain (ATCC VR-1584) and ZIKV Asian-American strain H/PAN/2015/CDC-259359 (ATCC VR-1859) stocks were generated in C6/36 mosquito cell cultures (ATCC CRL-1660) as indicated [26].

\subsection{Antiviral Assays}

\subsubsection{ZIKV Reporter Assay}

The initial screening for ZIKV was performed using the in-house developed infectious ZIKV reporter expressing Nanoluc (ZIKV PAN1 Nluc) (see details in SI). Briefly, $1.5 \times 10^{4}$ Huh7 cells per well were seeded in 96 well plates. Next day, cells were inoculated with the ZIKV reporter at a multiplicity of infection (MOI) of 0.2 in infection medium (MEM medium supplemented with $1 \%$ FBS, $100 \mathrm{IU}$ streptomycin/penicillin per $\mathrm{mL}, 1 \mathrm{mM}$ sodium pyruvate and $10 \mathrm{mM}$ HEPES). After $2 \mathrm{~h}$, the inoculum was replaced with post-infection medium (MEM medium supplemented with 5\% FBS, 100 IU streptomycin/penicillin per $\mathrm{mL}, 1 \mathrm{mM}$ sodium pyruvate and $10 \mathrm{mM}$ HEPES) containing compound of interest $(10 \mu \mathrm{M})$. We used the flavivirus NS5 MTase inhibitor NSC12155 ${ }^{13}(10 \mu \mathrm{M})$ and the NS5 RdRp inhibitor NITD008 ${ }^{12}(1 \mu \mathrm{M})$ as positive controls for inhibition or $0.05 \%$ DMSO as vehicle control. Seventy-two hours post-infection (hpi), the cells were lysed with $50 \mu \mathrm{L} 1 \times$ luciferase lysis buffer (Promega, Madison, WI, USA), incubated $10 \mathrm{~min}$ at room temp and stored at $-80^{\circ} \mathrm{C}$. Thirty-five $\mu \mathrm{L}$ of lysed cells were transferred to a white 96-well plate and combined with $35 \mu \mathrm{L}$ Nano-Glo ${ }^{\circledR}$ luciferase assay substrate (Promega) diluted 1:50 in Nano-Glo ${ }^{\circledR}$ luciferase assay buffer (Promega). The reaction was incubated for $2 \mathrm{~min}$ and luminescence readings were acquired using a Neo 2 plate reader (BioTek, Winooski, VT, USA). Percent inhibition was calculated in GraphPad Prism (San Diego, CA, USA) normalizing the luciferase signal to infected cells treated with DMSO ( $0 \%$ inhibition) and uninfected cells treated with DMSO (100\% inhibition). $\mathrm{EC}_{50}$ values were calculated in GraphPad Prism using data obtained from dose-response experiments. For compounds 1 and 8, a range of concentrations between 0.05 and $15 \mu \mathrm{M}$ were used. For compounds 11, 14, 23 and NSC12155, we used concentrations from 0.005 to $90 \mu \mathrm{M}$ and 0.002 to $45 \mu \mathrm{M}$ for NITD008.

\subsubsection{ZIKV and DENV Titer-Reduction Assay}

Selected compounds were validated at $8.5 \mu \mathrm{M}$ or $1.5 \mu \mathrm{M}$ (for compounds considered toxic at higher concentrations) using titer-reduction assays. Huh7 cells $\left(1.5 \times 10^{5}\right.$ per well $)$ were plated in 24-well plates. Next day, the cells were inoculated with ZIKV or DENV (MOI 0.2 or 0.05 , respectively) and two hours later, the inoculum was replaced with postinfection medium containing compound of interest at $8.5 \mu \mathrm{M}$ or $1.5 \mu \mathrm{M}$. Seventy-two hpi, supernatants from infected and treated cells were collected and viral titers were measured by plaque assay. To visualize plaques, confluent Vero cells in 24-well plates were inoculated with 1:10 serial dilutions of supernatants. After two hours, the inoculum was retired and replaced with $800 \mu \mathrm{L}$ of overlay medium (MEM medium containing 1.3\% methylcellulose, $2 \%$ FBS, $100 \mathrm{IU}$ streptomycin/penicillin per $\mathrm{mL}$ and $10 \mathrm{mM}$ HEPES). After 5 days (7 days for DENV), cells were washed with PBS, fixed with $2 \%$ formaldehyde, and stained using $0.5 \%$ crystal violet in $25 \%$ methanol. Infectious virus titer (pfu/mL) was determined using the following formula: number of plaques $\times$ dilution factor $\times(1$ /inoculum volume $(\mathrm{mL}))$. Viral titers were normalized with DMSO-treated and infected cells ( $0 \%$ inhibition). The limit of detection was $200 \mathrm{pfu} / \mathrm{mL}$ (100\% inhibition). For NITD008, we assigned 100\% inhibition because we did not detect any plaque at any dilution tested. Dose-response assays (Figure S4, Panels B and C) were performed for selected compounds using titerreduction assays. We used a concentration range of 0.5 to $15 \mu \mathrm{M}$ for all selected compounds except for compound 14 (range of $0.1-3 \mu \mathrm{M}$ ). Pfu/mL were normalized as mentioned for single-dose response experiment using the values for DMSO-treated and infected cells $(0 \%$ inhibition) and the limit of detection value $(200 \mathrm{pfu} / \mathrm{mL})$ as $100 \%$ inhibition. Dose-response curves were built in GraphPad Prism and EC $_{50}$ values were obtained from those curves. 


\title{
4.5. Cell Viability Assay
}

Cell viability assays for non-infected Huh7 cells treated with the testing compounds (in-house library), control compounds (NITD008, RDV) and DMSO were performed in parallel with the antiviral screening. After 3 or 5 days of treatment, depending upon the experiment, cell viability was evaluated using the MTS-based tetrazolium reduction CellTiter 96 Aqueous Non-Radioactive cell proliferation assay (Promega). Treatment was retired from the wells and the cells incubated with MTS diluted 1:10 in MEM medium supplemented with $10 \%$ FBS. Absorbance was measured at $490 \mathrm{~nm}$ wavelength. Readings were normalized with DMSO-treated cells $(100 \%)$ and expressed as \% viability. For doseresponse experiments, we used concentrations between 0.01 and $90 \mu \mathrm{M}$ and dose-response curves and $\mathrm{CC}_{50}$ were calculated using GraphPad Prism.

Supplementary Materials: The following are available online: Methods. Figure S1: Luciferase activity of serial dilutions of ZIKV PAN1 Nluc, Figure S2: The ${ }^{1} \mathrm{H}$ and ${ }^{13} \mathrm{C}$ chemical shifts of chloride 36a and the HMBC correlations observed, Figure $\mathrm{S} 3$ : The ${ }^{1} \mathrm{H}$ and ${ }^{13} \mathrm{C}$ chemical shifts of compound 29 and the HMBC correlations observed, Figure S4: Dose-response curves. Table S1: Primers and DNA sequences for pBAC ZIKV PAN1 NLuc construction Table S2: Sequence changes for pBAC-PAN1. NMR Spectra.

Author Contributions: L.C. and R.J.G. were responsible for designing the experiments and preparing the manuscript; L.C. and E.J. synthesized and characterized inhibitors; R.S.-A. performed the antiviral assays and edited manuscript; D.J.W. and L.Q. generated biological reagents used in the Zika reporter assay. All authors have read and agreed to the published version of the manuscript.

Funding: This research was funded by the National Institute of Allergy and Infectious Diseases, the National Institutes of Health, grant number R21AI151427 (to LC) and a University of Minnesota Academic Health Center Faculty Research Development Grant (to RJG).

Acknowledgments: We thank Paul D. Robbins and Fernando Santiago from the UMN Department of Biochemistry, Molecular Biology and Biophysics for the use of the Cytation One imaging system.

Conflicts of Interest: The authors declare that they have no known competing financial interests or personal relationships that could have appeared to influence the work reported in this paper.

Sample Availability: Samples of the compounds are available from the authors.

\begin{abstract}
Abbreviations
ABPP, activity-based protein profiling; DENV, Dengue virus; FDA, Food and Drug Administration; $\mathrm{HCV}$, hepatitis $\mathrm{C}$ virus; $\mathrm{HMBC}$, heteronuclear multiple bond correlation spectroscopy; HMQC, heteronuclear multiple quantum correlation; JEV, Japanese encephalitis virus; MOI, multiplicity of infection; MTase, methyltransferase; RdRp, RNA-dependent RNA polymerase; SAR, structure-activity relationship; WHO, World Health Organization; WNV, West Nile virus; YFV, Yellow fever virus; ZIKV, Zika virus.
\end{abstract}

\section{References}

1. Barrows, N.J.; Campos, R.K.; Liao, K.C.; Prasanth, K.R.; Soto-Acosta, R.; Yeh, S.C.; Schott-Lerner, G.; Pompon, J.; Sessions, O.M.; Bradrick, S.S.; et al. Biochemistry and molecular biology of flaviviruses. Chem. Rev. 2018, 118, 4448-4482. [CrossRef]

2. Shepard, D.S.; Undurraga, E.A.; Halasa, Y.A.; Stanaway, J.D. The global economic burden of dengue: A systematic analysis. Lancet Infect. Dis. 2016, 16, 935-941. [CrossRef]

3. Lim, S.P.; Wang, Q.Y.; Noble, C.G.; Chen, Y.L.; Dong, H.; Zou, B.; Yokokawa, F.; Nilar, S.; Smith, P.; Beer, D.; et al. Ten years of dengue drug discovery: Progress and prospects. Antiviral Res. 2013, 100, 500-519. [CrossRef] [PubMed]

4. Boldescu, V.; Behnam, M.A.M.; Vasilakis, N.; Klein, C.D. Broad-spectrum agents for flaviviral infections: Dengue, Zika and beyond. Nat. Rev. Drug Discov. 2017, 16, 565-586. [CrossRef] [PubMed]

5. Felicetti, T.; Manfroni, G.; Cecchetti, V.; Cannalire, R. Broad-spectrum flavivirus inhibitors: A medicinal chemistry point of view. ChemMedChem 2020, 15, 2391-2419. [CrossRef]

6. Lim, S.P. Dengue drug discovery: Progress, challenges and outlook. Antiviral Res. 2019, 163, 156-178. [CrossRef] [PubMed]

7. Gorshkov, K.; Shiryaev, S.A.; Fertel, S.; Lin, Y.W.; Huang, C.T.; Pinto, A.; Farhy, C.; Strongin, A.Y.; Zheng, W.; Terskikh, A.V. Zika virus: Origins, pathological action, and treatment strategies. Front. Microbiol. 2018, 9, 3252. [CrossRef] 
8. Mottin, M.; Borba, J.; Braga, R.C.; Torres, P.H.M.; Martini, M.C.; Proenca-Modena, J.L.; Judice, C.C.; Costa, F.T.M.; Ekins, S.; Perryman, A.L.; et al. The A-Z of Zika drug discovery. Drug Discov. Today 2018, 23, 1833-1847. [CrossRef]

9. Wang, L.; Liang, R.; Gao, Y.; Li, Y.; Deng, X.; Xiang, R.; Zhang, Y.; Ying, T.; Jiang, S.; Yu, F. Development of small-molecule inhibitors against Zika virus infection. Front. Microbiol. 2019, 10, 2725. [CrossRef] [PubMed]

10. Bernatchez, J.A.; Tran, L.T.; Li, J.; Luan, Y.; Siqueira-Neto, J.L.; Li, R. Drugs for the treatment of Zika virus infection. J. Med. Chem. 2020, 63, 470-489. [CrossRef] [PubMed]

11. Zou, J.; Shi, P.Y. Strategies for Zika drug discovery. Curr. Opin. Virol. 2019, 35, 19-26. [CrossRef]

12. Yin, Z.; Chen, Y.L.; Schul, W.; Wang, Q.Y.; Gu, F.; Duraiswamy, J.; Kondreddi, R.R.; Niyomrattanakit, P.; Lakshminarayana, S.B.; Goh, A.; et al. An adenosine nucleoside inhibitor of dengue virus. Proc. Natl. Acad. Sci. USA 2009, 106, 20435-20439. [CrossRef] [PubMed]

13. Brecher, M.; Chen, H.; Li, Z.; Banavali, N.K.; Jones, S.A.; Zhang, J.; Kramer, L.D.; Li, H. Identification and characterization of novel broad-spectrum inhibitors of the flavivirus methyltransferase. ACS Infect. Dis. 2015, 1, 340-349. [CrossRef]

14. Bakkestuen, A.K.; Gundersen, L.L.; Utenova, B.T. Synthesis, biological activity, and SAR of antimycobacterial 9-aryl-, 9arylsulfonyl-, and 9-benzyl-6-(2-furyl)purines. J. Med. Chem. 2005, 48, 2710-2723. [CrossRef]

15. Wang, S.B.; Deng, X.Q.; Liu, D.C.; Zhang, H.J.; Quan, Z.S. Synthesis and evaluation of anticonvulsant and antidepressant activities of 7-alkyl-7H-tetrazolo[1, 5-g]purine derivatives. Med. Chem. Res. 2014, 23, 4619-4626. [CrossRef]

16. Dong, H.; Chang, D.C.; Xie, X.; Toh, Y.X.; Chung, K.Y.; Zou, G.; Lescar, J.; Lim, S.P.; Shi, P.Y. Biochemical and genetic characterization of dengue virus methyltransferase. Virology 2010, 405, 568-578. [CrossRef] [PubMed]

17. Lim, S.P.; Sonntag, L.S.; Noble, C.; Nilar, S.H.; Ng, R.H.; Zou, G.; Monaghan, P.; Chung, K.Y.; Dong, H.; Liu, B.; et al. Small molecule inhibitors that selectively block dengue virus methyltransferase. J. Biol. Chem. 2011, 286, 6233-6240. [CrossRef] [PubMed]

18. Daffis, S.; Szretter, K.J.; Schriewer, J.; Li, J.; Youn, S.; Errett, J.; Lin, T.Y.; Schneller, S.; Zust, R.; Dong, H.; et al. 2'-O methylation of the viral mRNA cap evades host restriction by IFIT family members. Nature 2010, 468, 452-456. [CrossRef]

19. Leung, D.; Hardouin, C.; Boger, D.L.; Cravatt, B.F. Discovering potent and selective reversible inhibitors of enzymes in complex proteomes. Nat. Biotechnol. 2003, 21, 687-691. [CrossRef] [PubMed]

20. Yang, P.; Liu, K. Activity-based protein profiling: Recent advances in probe development and applications. Chembiochem 2015, 16, 712-724. [CrossRef]

21. Wright, M.H.; Sieber, S.A. Chemical proteomics approaches for identifying the cellular targets of natural products. Nat. Prod. Rep. 2016, 33, 681-708. [CrossRef]

22. Ziegler, S.; Pries, V.; Hedberg, C.; Waldmann, H. Target identification for small bioactive molecules: Finding the needle in the haystack. Angew. Chem. Int. Ed. Engl. 2013, 52, 2744-2792. [CrossRef] [PubMed]

23. Ai, T.; Qiu, L.; Xie, J.; Geraghty, R.J.; Chen, L. Design and synthesis of an activity-based protein profiling probe derived from cinnamic hydroxamic acid. Bioorg. Med. Chem. 2016, 24, 686-692. [CrossRef] [PubMed]

24. Chakka, N.; Bregman, H.; Du, B.; Nguyen, H.N.; Buchanan, J.L.; Feric, E.; Ligutti, J.; Liu, D.; McDermott, J.S.; Zou, A.; et al. Discovery and hit-to-lead optimization of pyrrolopyrimidines as potent, state-dependent Na(v)1.7 antagonists. Bioorg. Med. Chem. Lett. 2012, 22, 2052-2062. [CrossRef] [PubMed]

25. Frank, A.; Meza-Arriagada, F.; Salas, C.O.; Espinosa-Bustos, C.; Stark, H. Nature-inspired pyrrolo[2,3-d]pyrimidines targeting the histamine H3 receptor. Bioorg. Med. Chem. 2019, 27, 3194-3200. [CrossRef] [PubMed]

26. Qiu, L.; Patterson, S.E.; Bonnac, L.F.; Geraghty, R.J. Nucleobases and corresponding nucleosides display potent antiviral activities against dengue virus possibly through viral lethal mutagenesis. PLoS Negl. Trop. Dis. 2018, 12, e0006421. [CrossRef] 